University of Louisville

ThinkIR: The University of Louisville's Institutional Repository

Electronic Theses and Dissertations

$8-2010$

\title{
Munc13-3 mutation prevents critical period neuronal plasticity in visual cortex.
}

James Geoffrey Morris 1984-

University of Louisville

Follow this and additional works at: https://ir.library.louisville.edu/etd

\section{Recommended Citation}

Morris, James Geoffrey 1984-, "Munc13-3 mutation prevents critical period neuronal plasticity in visual cortex." (2010). Electronic Theses and Dissertations. Paper 1008.

https://doi.org/10.18297/etd/1008

This Master's Thesis is brought to you for free and open access by ThinkIR: The University of Louisville's Institutional Repository. It has been accepted for inclusion in Electronic Theses and Dissertations by an authorized administrator of ThinkIR: The University of Louisville's Institutional Repository. This title appears here courtesy of the author, who has retained all other copyrights. For more information, please contact thinkir@louisville.edu. 


\title{
MUNC13-3 MUTATION PREVENTS CRITICAL PERIOD NEURONAL PLASTICITY IN VISUAL CORTEX
}

\author{
By \\ James Geoffrey Morris \\ B.A., Miami University, 2007
}

\begin{abstract}
A Thesis
Submitted to the Faculty of the Graduate School of the University of Louisville in Partial Fulfillment of the Requirements for the Degree of
\end{abstract}

Master of Science

Department of Anatomical Sciences and Neurobiology University of Louisville Louisville, Kentucky

August 2010 

MUNC13-3 MUTATION PREVENTS CRITICAL PERIOD NEURONAL PLASTICITY IN VISUAL CORTEX

\author{
By \\ James Geoffrey Morris \\ B.A., Miami University, 2007 \\ A Thesis Approved on
}

July 30,2010

by the following Thesis Committee

Thesis Director 


\section{DEDICATION}

This thesis is dedicated to my parents,

Mr. Rick and Mrs. Julie Morris, and two siblings,

Drew and Becky Morris,

for all of the love and support they have shown me, and Marian Eldridge, who has patiently helped, loved and supported me. 


\section{ACKNOWLEDGEMENTS}

I would like to give my thanks to my mentor, Dr. George Mower, for the support and willingness to let me work with him in his lab, and for all of his help and advice throughout my Master's education. I would also like to thank my committee members, Dr. Charles Hubscher for the help with the thesis and supporting me by being a part of my committee and Dr. Woody Petry for all of his help and advice that got me through this project, as well as use of his equipment and aid. I would also to thank Dr. Cuibo Yang who has been a great friend and enjoyable to work with in the lab and to Dr. Paul

Kiser, whose help and support kept my project going throughout my time in the lab and for the friendship that he has shown me. 


\title{
ABSTRACT \\ MUNC13-3 MUTATION PREVENTS CRITICAL PERIOD NEURONAL PLASTICITY IN VISUAL CORTEX
}

\author{
James G. Morris
}

July 30,2010

Through differential display PCR, Munc13-3 was identified as a gene whose relative expression in the visual cortex corresponds to critical period plasticity.

Expression of the gene was low at the peak of the critical period and expression was high in the weeks near the end of the critical period. Expression of the gene also shifted during dark rearing, a process known to delay the time course of the critical period. Using electrophysiology and monocular deprivation (MD) in mice at different points within the critical period, it is possible to compare normal MD mice's visual evoked potentials to Munc13-3 mutant MD mice's visual evoked potentials to see what effect Munc13-3 has on visual cortical plasticity.

Visual evoked potentials from the eyes contralateral and ipsilateral to the recording electrode in the binocular region of the visual cortex were stimulated and recorded in normal wildtype mice, monocular deprived mice and monocular deprived Munc13-3 mutants at ages 3.5 weeks and 9 weeks. At 3.5 weeks age the normal wildtype mice showed a large contralateral and smaller ipsilateral response, monocular deprived mice showed the same size ipsilateral (non-deprived eye) response, but a smaller contralateral (deprived eye) response. The monocular deprived Munc13-3 mutant mice showed the same as the normal mouse, large contralateral (deprived eye) response and 
small ipsilateral (non-deprived eye) response. At 9 weeks of age the normal mice showed the same pattern as the 3.5 week old mice, the monocular deprived mice showed an increased ipsilateral response but no change in contralateral response and the monocular deprived Munc13-3 mutants showed no difference in response compared to the normal mice.

Monocular deprivation causes a decreased responsiveness from the contralateral eye in young mice, but causes an increased responsiveness from the ipsilateral eye in the adult mice. Munc13-3, a gene seen to be involved with short term synaptic plasticity and vesicle and neurotransmitter release, mutants do not have any change after monocular deprivation, so plasticity is lost. Munc13-3 gene is therefore involved in the regulation of visual cortical plasticity and is required, most likely in conjunction with other genes, to maintain plasticity in the visual cortex during the critical period. 


\section{TABLE OF CONTENTS}

PAGE

DEDICATION

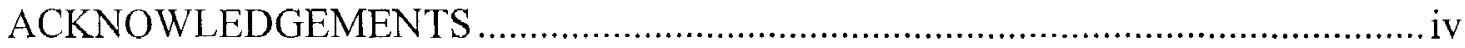

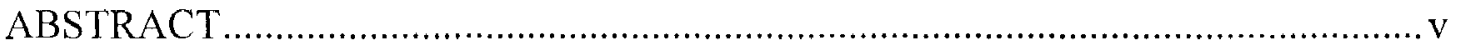

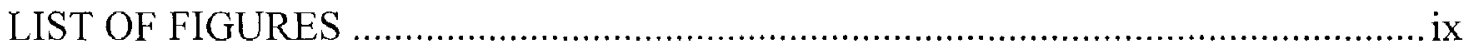

INTRODUCTION

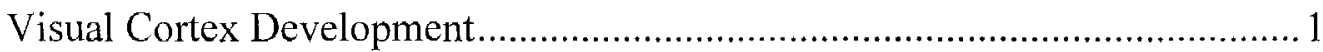

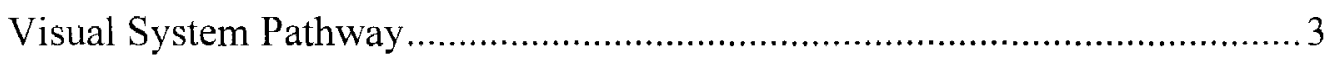

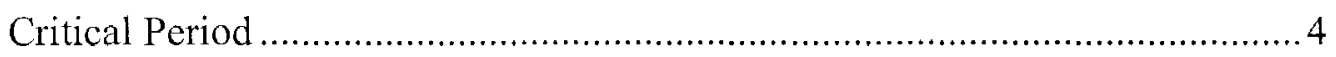

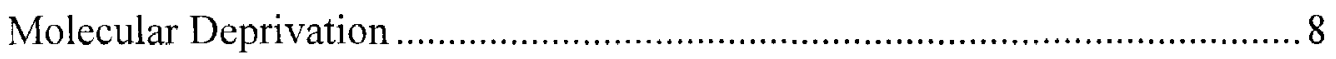

Munc13-3 Mutation and Plasticity .................................................................13

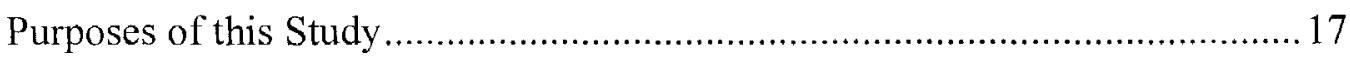

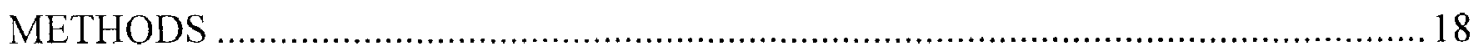

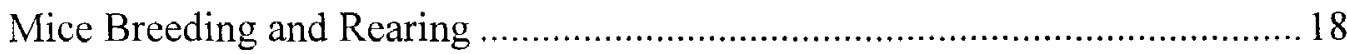

Electrode Implantation Procedure................................................................. 19

Monocular Deprivation Procedure....................................................................22

Visual Evoked Potentials Recording ………………………………….........25

Visual Evoked Potential Analysis...............................................................26

Electrode Placement Identification ...............................................................2

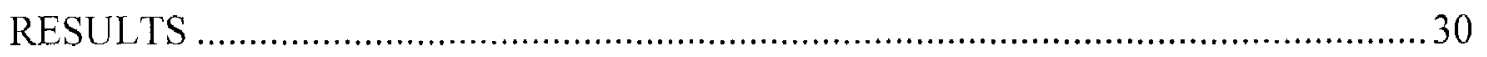

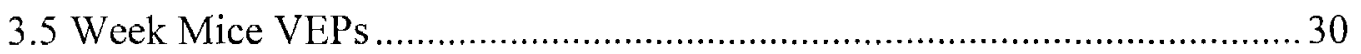


3.5 Week Mice Contralateral to Ipsilateral Ratios............................................. 38

3.5 Week VEP Contralateral to Ipsilateral Comparisons.....................................38

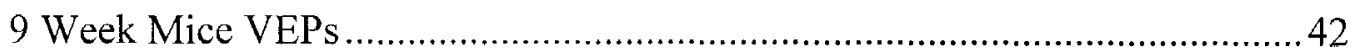

9 Week Mice Contralateral to Ipsilateral Ratios ...................................................45

9 Week Mice Contralateral to Ipsilateral Comparisons ......................................50

Latency, Impedance and Electrode Placement ……….....................................53

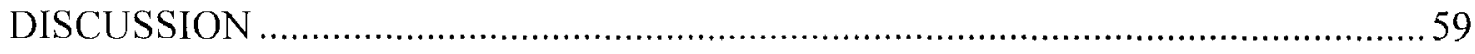

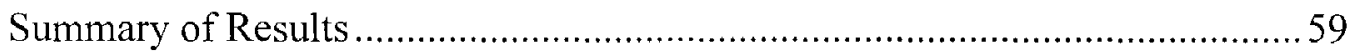

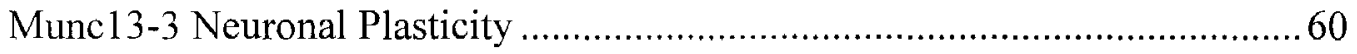

Visual Evoked Potentials and Monocular Deprivation Difficulties.................... 63

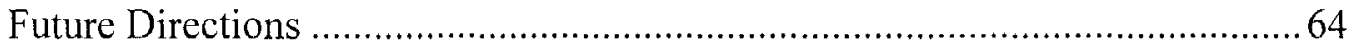

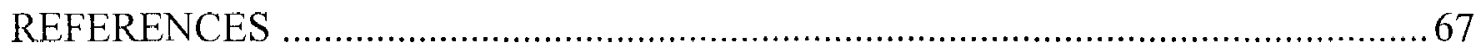

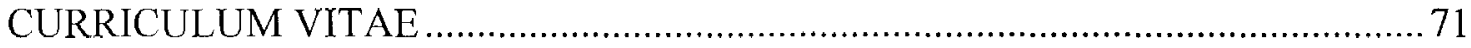




\section{LIST OF FIGURES}

FIGURE

PAGE

1. Effects of dark rearing on the visual cortex ..................................................... 7

2. Monocular deprivation effects on young versus old mice ................................ 12

3. Relative expression of munc13 isoforms in the visual cortex ............................. 16

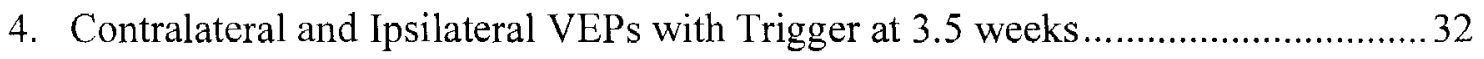

5. Visual evoked potentials of both eyes open and blocked at 3.5 weeks ....................35

6. VEPs of the contralateral and ipsilateral eye only of each condition at 3.5 weeks .37

7. Contralateral to ipsilateral VEP ratio and relative VEP comparisons at 3.5 weeks. 41

8. Contralateral and Ipsilateral VEPs with Trigger at 9 weeks .............................4 44

9. Visual evoked potentials of both eyes open and blocked at 9 weeks ...................47

10. VEPs of the contralateral and ipsilateral eye only of each condition at 9 weeks ....49

11. Contralateral to ipsilateral VEP ratio and relative VEP comparisons at 9 weeks....52

12. Relative recovery of contralateral to ipsilateral ratio from monocular deprivation. 55

13. Lesion of electrode placement in binocular region of visual cortex ......................58 


\section{INTRODUCTION}

Neuronal plasticity in the visual cortex, a term developed from Hubel and Wiesel's critical period (Hubel et al., 1977), is regulated by genes like all other anatomical and physiological processes. Genes of visual cortical neuronal plasticity were identified through a rigorous analysis of genes present in the visual cortex and the changes in expression of those genes compared to the critical period timeline. If a particular gene matched a pattern that corresponded to the critical period changes, it was identified as a candidate gene for visual plasticity. Dab-1 and Munc13-3 have both been identified as candidate genes that relate to controlling the neuronal plasticity of the critical period (Yang et al., 2002; Yang et al., 2006; Yang et al., 2007). This introduction will review general information involving the development of the visual cortex and plasticity, primarily focus on Munc13-3 candidate gene for plasticity as it is the basis of the experiment, and discuss the techniques and results from monocular deprivation electrophysiological analysis.

Visual Cortex Development

The development of the visual cortex occurs by a budding out from an initial basal layer causing the earlier developed cells to be on inside deeper section of the cortex and causing the later developed cells to migrate towards the outer surface of the cortex. 
During this embryological developmental process of the visual cortex, six distinct layers identified by the size, amount and properties of cells in the gray matter in the cortex are formed from the migrating cells (Garey, 1971; Garey and Powell, 1971; Hubel and Wiesel, 1972). Layer VI is the earliest to develop followed by the layer V and layer IV. Layer IV is where the primary synapse occurs from neurons from the lateral geniculate nucleus. Layers II and III develop over a longer period of time and receive the input signals generated by layer IV. Layers II and III then synapse with layers V and VI into columnar groups. Each of these columnar groups correspond to the small section of the visual field observed, creating essentially a one to one map in all layers of what is being seen in the corresponding visual field, within Brodmann's area 17 (Lund et al., 1975; Tusa et al., 1978; Gilbert and Wiesel, 1979).

Specific neurons within the primary visual cortex respond only to stimulation to the eye contralateral in the hemisphere being tested. This is deemed the monocular segment of the retinotopic map of Brodmann's area 17. Other neurons respond to stimuli from both eyes, and are therefore called the binocular segment. These binocular segments do however show a preference for stimulation from the contralateral eye indicating a particular ocular dominance seen in these binocular regions (Lowel and Singer, 1987). Shatz's staining of the neuronal projections from the lateral geniculate nucleus to layer IV in the cat shows stained clusters in that cortical layer representing a specific eye. An alternating pattern of stain and unstained regions of layer IV showed that there was a specific anatomical feature called ocular dominance columns corresponding to a specific eye. Evidence shows that these columns are anatomical 
representations of specific inputs from a single eye that stain in an alternating pattern showing ipsilateral and contralateral staining in the binocular region and contralateral staining only in the monocular region (Shatz et al., 1977).

Visual System Pathway

The visual pathway is the route taken from a specific point stimulated on the retina all the way to layer IV of the primary visual cortex. The visible light passes through the layers of the ganglion and bipolar cells on the inner surface of the retina and causes a chemical reaction to occur in the corresponding rod or cone light receptor. The photoreceptor generates a potential that is transmitted to the bipolar cell, which innervates ganglion cell. The ganglion cells' axons group together to form cranial nerve II, the optic nerve.

The optic nerves cross at the optic chiasm and decussate into optic tracts containing respective visual fields; the contralateral eye's nasal retina and ipsilateral eye's temporal retina group to form the left visual field and travel to the right hemisphere and vice versa. The optic tracts synapse in the lateral geniculate nucleus into distinct layers representing each eye in the dorsal section. In the macque monkey layers 2,3 and 5 contain synapses from fibers from the ipsilateral eye, where layers 1,4 and 6 receive fibers synapsing from the contralateral eye input. The optic radiations from the lateral geniculate nucleus synapse in the layer IV of the primary visual cortex found in the occipital lobe. Layer IV is where the inputs of the eyes are organized into the ocular 
dominance columns previously discussed, corresponding to inputs from either the contralateral eye, or from both the contralateral and ipsilateral eye.

\section{Critical Period and Dark Rearing}

Critical period studies all stemmed from the research of Hubel and Wiesel where the cortex was found to be modifiable by differing deprivation experiences and the index of this effect varied between certain periods of time (Hubel and Wiesel, 1970). A critical period was determined to exist between a stage early in postnatal development that allows for anatomical and physiological changes to occur. This period of time is variable among animal species but always occurs at some point.

The cat is one of the best models for identification of plasticity and critical period in the visual cortex. Just after birth the cat brain is still in developmental stages with the presence of embryonic cells. During a course of several weeks the cells migrate to the final position and differentiate into specific cell types. They also form ocular dominance columns during this period of time (Shatz and Luskin, 1986). Synaptogenesis occurs during this same period, whereby new synapses are increasingly formed from birth to a period of four to five weeks and eventually decrease to levels found in adult cats over the following months (Cragg, 1975; Winfield, 1983).

Ocular dominance columns are formed in cats after two weeks postnatally and are found to be functionally active by week six (LeVay et al., 1978; Crair et al., 2001). 
During this 2 to 6 week functional period, the cat's visual cortex is susceptible to changes through monocular deprivation. The period of plasticity ends its sensitivity to such conditions at around 12 to 16 weeks of age in cats (Mower and Christen, 1985). This period, where the developmental plasticity is at its point of highest ability for change and is dependent upon visual experience, is deemed the critical period. Monocular deprivation is a key to studying the visual experience. By occluding a single eye, the response to stimuli changes and so does the relative amount of recovery, both depending on specific time period during development. This allowed for the comparative study of periods of plasticity and amount of change that occurred due to occlusion of the deprived eye. Monocular deprivation and its effect on the plasticity of the visual cortex in mice will be discussed later in this section, but first the effect of dark rearing on the critical period must be discussed.

Dark rearing involves depriving the animal from any kind of light, hindering visual experience for an extended period of development starting from birth. Depriving the animal from visual experience causes developmental changes to the visual cortex maturing process. For example, ocular dominance columns remain in a state of immaturity and do not segregate in dark reared animals as opposed to normal reared (Mower et al., 1985). Dark rearing is also seen to extend the critical period of neuronal plasticity, showing that it is the visual experience that drives the critical period not necessarily a specific time course of development. Dark rearing also extends the period of time of susceptibility to monocular deprivation showing that the brain remains in a 
Figure 1. This shows the time course of the critical period normally and the time course of the change in the critical period due to dark rearing. The normal condition in the cat shows that the peak of the critical period occurs at 5 weeks of age, where dark reared cats show a delay in the peak of the critical period to around 12 weeks of age (Mower, 1991). 


\section{Dark Rearing and the Critical Period}

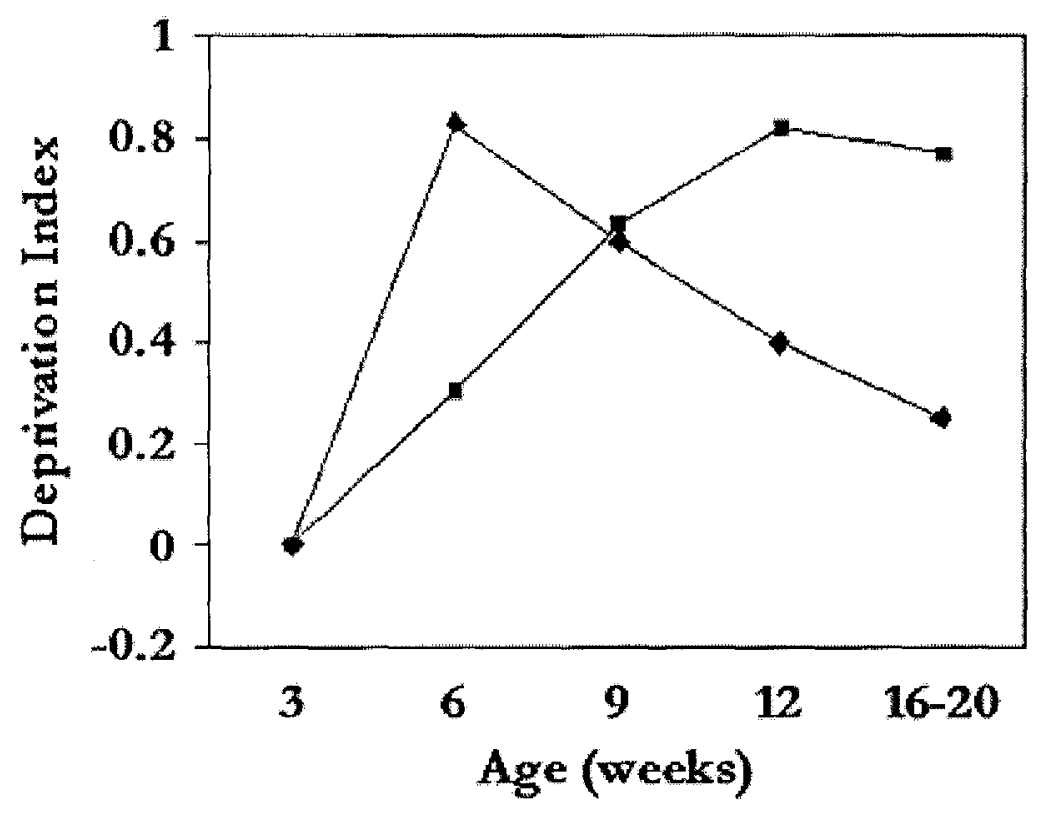

Figure 1

(Mower, 1991) 
more plastic state for longer (Cynader and Mitchell, 1980; Mower et al., 1981; Mower, 1991).

Monocular Deprivation

Monocular deprivation is the process of complete suture of either the dominant contralateral eye or the nondominant ipsilateral eye to test the plasticity responsive changes in the visual cortex and its corresponding pathways. Changes are noted both anatomically and physiologically as shifts away from the normal. Anatomical effects have shown that the extragranular layer has a role in responsiveness to monocular deprivation, specific layers of the visual cortex allow for more plastic changes to occur, and changes in the relative sizes of ocular dominance columns in the deprived and nondeprived eye (Shatz and Stryker, 1978; LeVay et al., 1980; Mower and Christen, 1985; Daw et al., 1992).

Physiological effects relate to the anatomical changes occurring and allow for tests to be run on live animals, enabling observations of changes due to monocular deprivation before, during and after occlusion of the eye. Early experiments showed that during the critical period, surgical monocular deprivation of an eye will cause a decreased responsiveness to that eye in the binocular regions of the visual cortex (Hubel et al., 1977). In some cases monocular occlusion results in the complete loss of functional responsiveness to experience of that eye and responds only to the non-deprived eye (Hubel et al., 1977; Olson and Freeman, 1980). Results from long term monocular 
deprivation studies such as those on the macque monkey often resulted in a complete irreversible result due to the occlusion lasting beyond the critical period. Cats monocularly deprived from birth to nearly eight months result in an overwhelming amount of responsiveness to only the nondeprived eye. This is contrary to what is normally seen to be high binocular responsiveness in most cells in the cat brain (Shatz and Stryker, 1978).

During the critical period, where plasticity remains high, it was found that after monocular deprivation, the opening of the deprived eye resulted in the recovery of some of the responsiveness to the deprived eye over a period of time (Mitchell, 1988). However, if the period of the deprivation is extended beyond that particular animal's critical period, the results remained to show little to no responsiveness in the deprived eye and no recovery noted (Mitchell, 1988). Monocular deprivation in rats shows that there is a similar physiological effect and confirms that extension of the critical period through dark rearing evokes a robust effect similar to that of a normal young rat (Guire et al., 1999). This further implicates that the critical period of visual plasticity is paramount for changes in responses due to monocular deprivation. This allows for further studies into the mechanisms and genes that regulate critical period plasticity and the control they have over the physiological changes that occur from monocular deprivation during this period.

In mice, the animal used for this particular study, the ideal time period for monocular deprivation was determined to be 5 days. Sawtell et al. found that three days 
monocular deprivation in the adult mice was insufficient in generating a significant difference between contralateral and ipsilateral response compared to a normal mouse (Sawtell et al., 2003). Following five days of monocular deprivation, the young mice and adult mice yield significantly different results seen in Figure 2 (Sawtell et al., 2003). The figure represents an ideal comparison to what's hoped to be replicated and compare with our mutant tests. In figure 2, monocular deprivation in the young mice, at P28, yielded significantly depressed responses in the deprived contralateral eye, consistent with the thought that monocular deprivation causes a depression of responsiveness in the deprived eye. The adult mice, recorded between P72 and P90, showed no significant decrease in the responsiveness of the deprived contralateral eye, but they showed significantly increased responsiveness in the ipsilateral eye (Sawtell et al., 2003; Cho et al., 2009). Also noted was the physiological recovery observed in the mice, where after the onset of the monocular deprivation and exposure, the contralateral to ipsilateral ratio increases towards the normal ratio observed in adult mice (Sawtell et al., 2003).

With the established physiological effects of monocular deprivation during the critical period of plasticity, it is now necessary to discuss and examine the genes and mechanisms that may regulate these changes. Increasing evidence has made it clear that subunits of the NMDA receptor are responsible for many of the regulatory effects of plasticity (Cho et al., 2009). Discovery of the genes responsible for regulating any kind of plasticity changes requires the testing of gene knockout animals that reflect a particular pattern of expressiveness that indicates involvement in plasticity of the critical period. 
Figure 2. MD effect recorded from both adult and young mice, showing previous established MD effect compared to the baseline. The adult mouse shows an increased responsiveness to the ipsilateral eye, where the young mouse shows a decreased responsiveness to the contralateral, deprived eye (Sawtell et al., 2003). 


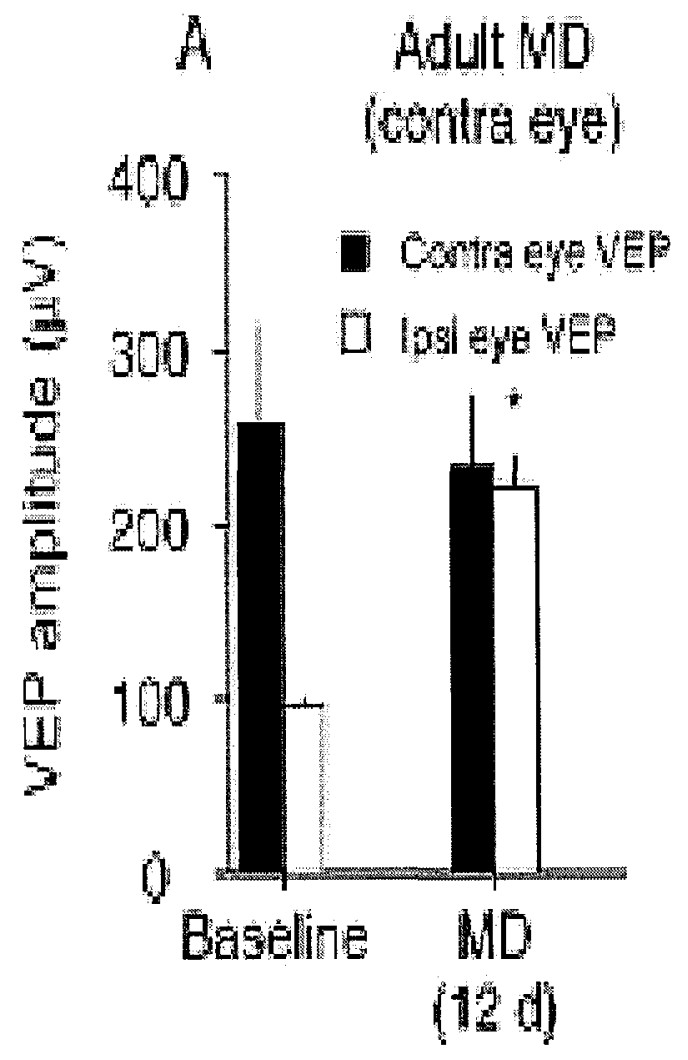

Figure 2
B roung MD (contra sye)

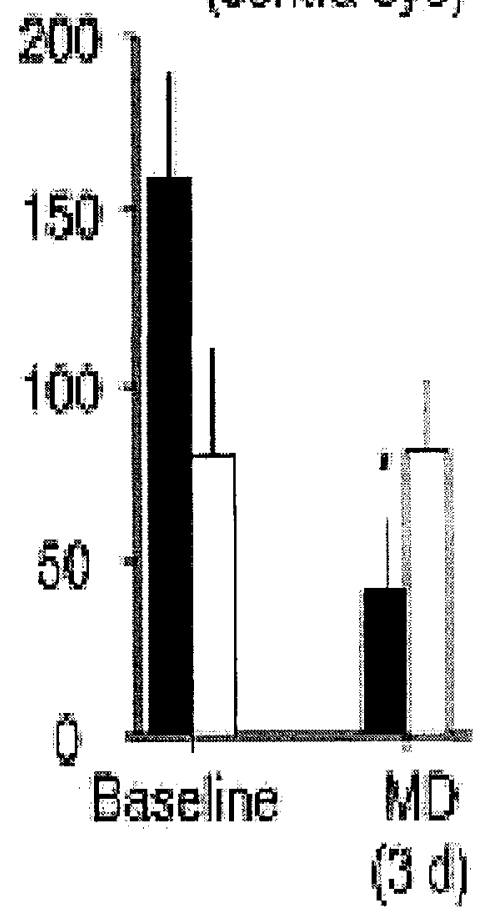

(Sawtell et al., 2003) 
Munc13-3 Mutation and Plasticity

Yang et al. used a process of differential display PCR combined with specific criteria for identifying genes related to plasticity during the critical period by comparing relative expressions between different candidate genes. The criterion was built from a comparison between normal and dark reared cats because the peak of the critical period is delayed in the dark reared cat. This makes it possible to identify genes whose expressions responds to the delay and are therefore related to the critical period (Yang et al., 2001; Yang et al., 2002; Yang et al., 2006; Yang et al., 2007). There are two specific patterns of expressions in the ddPCR that would show a relationship to plasticity in the critical period. A plasticity gene is defined as being high at during the critical period at around 5 weeks and low when past the critical period at 20 weeks and dark reared should be higher in latter, at 20 weeks, and lower at 5 weeks, because of the delay in the critical period peak. Anti-plasticity genes are just the opposite, opposing the plasticity by having low expression during plastic periods and high expression during less plastic periods (Yang et al., 2001; Yang et al., 2002; Yang et al., 2006; Yang et al., 2007).

Munc13-3 was one gene identified to show the pattern of expression of an antiplasticity gene in the visual cortex. Figure 3 shows the pattern of expression of munc133 in the in visual cortex compared to that of its other isoforms, munc13-1 and munc13-2 (Yang et al., 2002). Regional distribution of the munc13-3 was tested in the throughout the brain and was found to be greatly expressed in the cerebellum, but also showed expression in the visual cortex (Yang et al., 2007). The bidirectional expression of the 
munc13-3 however was found to be specific to the visual cortex (Yang et al., 2007). This means that the munc13-3 gene is found in the visual cortex and only shows the antiplasticity pattern in the visual cortex. Therefore it is likely that munc13-3 plays a role in plasticity in the visual cortex, being either a plasticity repressor or works in conjunction with other plasticity genes to maintain a state of both plasticity and non-plasticity during and after the critical period.

Munc13-3 is part of the unc-13 gene family that is seen to be expressed throughout the brain, with munc13-3 mostly being observed caudally (Brose et al., 1995; Augustin et al., 1999b; Yang et al., 2002). All three isoforms of the munc13 gene are found to be involved in the regulation of exocytosis of synaptic vesicles and thus involved in neurotransmitter release, particularly glutamate (Augustin et al., 2001; Basu et al., 2007). Growing evidence also related to exocytosis is that munc13 most likely has some control over short term synaptic plasticity, possibly by modifying the release rate of synaptic vesicles through modification of calcium channels (Junge et al., 2004; Zikich et al., 2008). Given munc 13-3's relationship to short term plasticity effects, its role in the release of synaptic vesicles, and especially after identifying its bidirectional expression, it is easy to assume that munc13-3 could have a very important role in critical period plasticity of the visual cortex,. 
Figure 3. This figure shows the relative expression of each of the Munc13 isoforms, under normal (N) and dark-reared (D) conditions at 5 and 20 weeks of age. The Munc133 shows the "anti-plasticity" pattern of low expression when young, high expression when old and the opposite of that when dark-reared due to the prolonged delay of the critical period (Yang et al., 2002). 


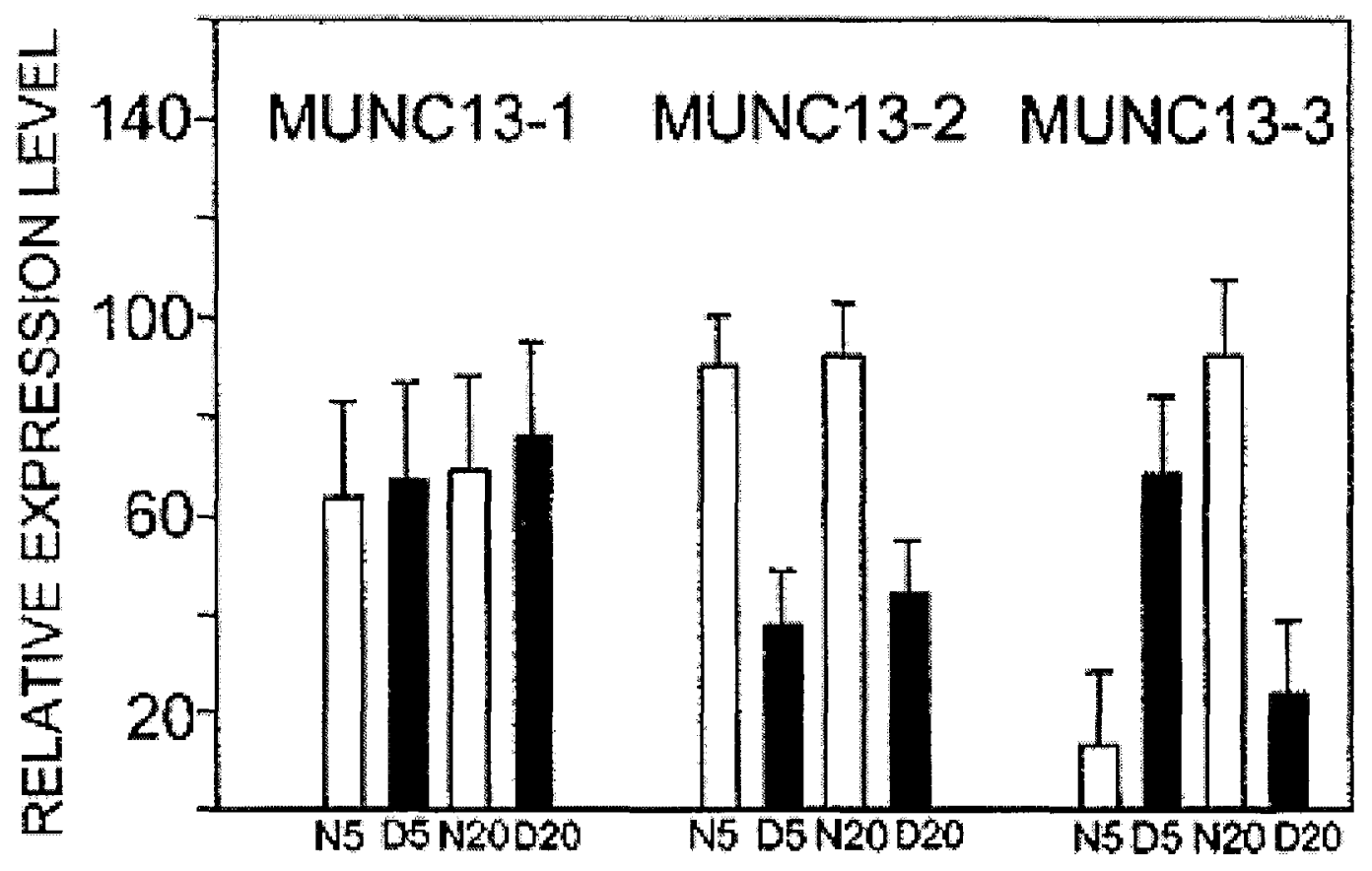

Figure 3

(Yang et al., 2002) 
Purpose of Study

The purpose of this study is to use monocular deprivation to replicate the electrophysiological effects seen in previous studies and apply it to munc13-3 knockout mutants. These mice would be used to record visual evoked potentials from both normal and monocular deprived mice from wildtype and munc13-3 mutant groups at 3.5 weeks and 9 weeks of age. Doing so will establish what kind of effect, if any, does the munc133 gene, a gene involved in synaptic transmission, has on the plasticity changes due monocular deprivation. 


\section{METHODS}

Mice Breeding and Rearing

Heterozygous Munc13-3 mice knockout mice were provided to us for mutant rearing purposes from Dr. Nils Brose (Department of Molecular Neurobiology, Max Planck Institute of Experiment Medicine, Göttingen, Germany). The mice were reared according to the guidelines of the National Institutes of Health and approved by the Institutional Animal Care and Use Committee while being kept at the University of Louisville School of Medicine Research Resource Center. Homozygous Munc13-3 mice for the knockout gene and wildtype homozygous mice were set as breeding pairs after PCR genotyping identification. Pups produced by the pairs were ear-tagged and identified through the multiplex PCR genotyping as well to confirm the knockout mutation.

Munc13-3 mutant mice and normal wildtype mice were raised at the Research Resource Center maintaining a normal rearing pattern of 12-hour light to dark cycles simulating regular daily rhythms of light. For experimental purpose, mice from both the homozygous wildtype and homozygous Munc13-3 knockout were used at both 3.5 weeks and 9 weeks. Mice used 3.5 weeks were removed for experiment approximately three and a half days into the weaning period. Mice used at 9 weeks age were weaned at the 
same time as the younger experimental mice, but continued to be raised at the Research and Resource Center until reaching the final experimental age of 9 weeks.

Munc13-3 mice used for experiments stated in the following procedures eventually had full headgear with recording electrodes, indifferent electrodes and fixing post attached to the scalp and skull. Leaving the mice in the normal cages with the overhanging wire food and water bottle posed a posed a problem were it was possible for the "skull cap" to be snagged or caught. Post-surgical electrode implanted mice were alleviated of this issue by providing the food pellets on the floor of the cage and the introduction of a gel-based water source titled "Napa Nectar" to supply as the water necessary for survival. Post-surgical mice adapted to the new sources of food and water relatively quick, with the older mice being the slowest to adapt. "Napa Nectar" was decided to be introduced a few days pre-surgical procedures to help induce a better transition of primary water sources.

Munc13-3 mice, following VEP recordings, were overdosed with the ketamine/xylazene injection solution and then perfused with the $37^{\circ} \mathrm{C}$ PBS solution followed by paraformaldehyde documented in detail in the methods for tissue collection and electrode placement identification. 
The following protocol was developed by the laboratory of Mark Bear, $\mathrm{PhD}$ (MIT, Cambridge, MA) and was refined for our lab by Paul Kiser, PhD (ULSOM, Louisville, $\mathrm{KY}$ ) and conformed to the guidelines for test animals instituted by the National Institute of Health and approved by the Institutional Animal Care and Use Committee. Lab 60Sn/40Pb soldered silver wire (\#782500, A-M Systems INC., Everett, WA) with gold male connector pins (\#520200, A-M Systems INC., Everett, WA) were produced as indifferent electrodes. Tungsten recording microelectrodes (\#UEWSECBN1C, FHC, Bowdoinham, ME) were measured for impedance before implantation by the FHC NeuroCraft Impedence Conditioning Module (\#55-70-0, FHC, Bowdoinham, ME) to make sure identified impedance was within an adequate range inbetween 0.30 to $0.49 \mathrm{~m} \Omega$. Wire nails (\#18,3/4" flathead nail) were cut and filed to approximately $1 \mathrm{~cm}$ in length to provide a dull head for maintaining the mice head in a fixed position.

Using a 90mg/kg Ketamine and $9 \mathrm{mg} / \mathrm{kg}$ Xylazine mixture, mice were anesthetized throughout the entire procedure while maintaining constant awareness of both body temperature and heart rate. Supplemental "booster" injections of a Ketamine $90 \mathrm{~kg} / \mathrm{mg}$ solution were used to maintain anesthesia if the mice level of arousal increased during the surgical procedure. After the mice were anesthetized in a deep level with no twitch reflexes apparent, a sterile ophthalmic ointment (Puralube, NDC17033-211-38, Dechra Veterinary Products, Overland Park, KS) was applied to each eye to prevent corneal desiccation throughout both the surgery and recovery period while the blinking reflex was lost. 
After a deep level of anesthesia was obtained, a $0.1 \mathrm{ml}$ of $0.05 \%$ Lidocaine injection solution was given just under the scalp which would be removed allowing for increased pain relief throughout the procedure. Following a mid-saggital incision from the rostral part of the skull just before the point on the skull designated "bregma" to past the point designated "lambda," approximately $3.5 \mathrm{~mm}$ of tissue was removed from both sides exposing an oblong oval view of the skull. A periosteal membrane situated above the skull was exposed as a gelatinous membrane. Much of the membrane was carefully cut away with fine surgical scissors, while the remaining was scraped away by the broad edge of a scalpel blade. The skull was cleaned initially by sterile cotton swabs, and then by a $70 \%$ EtOH swab to help promote drying of the exposed skull.

After approximately 15 minutes of drying, the $1 \mathrm{~cm}$ fixation post was adhered to the most rostral section of the exposed skull with a liquid cyanoacrylate adhesive (Loctite-495, Loctite Corp, Rocky Hill, CT). The now glued fixed post was adhered and cured quickly by the application of a single drop of ZipKicker cyanoacrylate accelerator (Pacer Technology, Ranch Cucamonga, CA). Following the drying of the fixation post to the skull, the mouse was attached for the rest of the procedure to a custom designed acrylic stereotaxic base (University of Louisville machine shop).

Using a high speed micro drill (\#18000-17, Fine Science Tools (USA) INC., Foster City, CA) with a $0.7 \mathrm{~mm}$ burr bit (\#19008-07, Fine Science Tools (USA) INC., Foster City, CA), a small hole was drilled $1 \mathrm{~mm}$ lateral to "bregma" in the same side of the brain the recording electrode was intended to be placed. The reference electrode was 
placed into the drilled hole and fixed to the skull by a gel-based cyanoacrylate adhesive (Loctite-454, Loctite Corp, Rocky Hill, CT) and was accelerated by ZipKicker. Measuring using the stereotaxic position from our apparatus, the recording electrode placement is $3 \mathrm{~mm}$ lateral to "lambda." This allowed for position of the microelectrode to be in the binocular region of the mouse visual cortex. A hole was made by the same rotary tool and bit at this position by making concentrically deeper circles around the electrode placement area. This allows for the skull the become thin enough that a sterile hypodermic needle and micro-forceps can be used to removed the small section approximately $1 \mathrm{~mm}$ in diameter of skull away from the brain. Any blood from the removal of the skull was absorbed by absorbent paper points (\#71011-02 Electron Microscopy Sciences, Washington, PA).

The tungsten recording microelectrode was lowered into the hole by the stereotaxic apparatus to the point that the electrode is touching the dura mater of target binocular region of the visual cortex. A gentle tap was given to the apparatus to perforate the dura mater and allow for easy entry of the recording electrode into the brain. The electrode was lowered approximately $450 \mu \mathrm{m}$ into the target region of the visual cortex. Using the same gel-based adhesive, the recording electrode was secured to the skull and accelerated with ZipKicker. The guide wire of the recording electrode was trimmed with wire cutters to the resin point. Careful consideration was taken into account to not allow the lead wire of the recording electrode to touch any part of the skull in order to reduce any potential interference. The rest of the lead wire of the recording electrode was 

surrounded by the gel-based cyanoacrylate adhesive up to the gold male electrode and dried by the accelerant ZipKicker.

The final part of the procedure involved removing the mouse from the stereotaxic apparatus and replacing the entire exposed skull. The entirety of the exposed part of the mouse skull, including the bases of the fixation post and electrode attachment points, was carefully covered by non-conductive two part rapid setting dental acrylic (OrthoJet Liquid \#1304, methyl methacrylate monomer and OrthoJet Acrylic Resin Powder, \#1300, Lang Dental Manufacturing Co. INC. Wheeling, IL). When dried, this created an acrylic cap that protected the placement of the electrodes, as well as provided a barrier protecting the mouse from infection and the cut edges of the scalp from retraction. Until the blink reflex was restored, the mice eyes were continually covered by the ophthalmic ointment.

During recovery and the following days, the mice were given a 24 hour analgesic dosage of $4 \mathrm{mg} / \mathrm{kg}$ Ketoprofen. Mice also recovered on heating pad to maintain adequate body temperature until they were semi-alert, where they were returned to their cages. The mice were monitored for the remainder of the experiment for signs of discomfort and infection, and allowed to be adequately comfortable with the recording apparatus a day prior to the initial start of recording.

\section{Monocular Deprivation}


All procedures were performed in accordance with the guidelines set by the National Institute of Health and were approved by the Institutional Animal Care and Use Committee. Mice scheduled for monocular deprivation studies were anesthetized five days before implantation of recording microelectrode and the start of recording visual evoked potentials. Mice were anesthetized according to body weight with a $90 \mathrm{mg} / \mathrm{kg}$ Ketamine and $9 \mathrm{mg} / \mathrm{kg}$ Xylazine injection solution. In order to prevent any corneal desiccation, a sterile ophthalmic ointment (Puralube, NDC17033-211-38, Dechra Veterinary Products, Overland Park, KS) was applied to both eyes. Following loss of reflex movements the eye contralateral to the hemisphere designated for electrode implantation, the skin around the eye was wiped clean by a $70 \%$ ethanol to help provide a sterile area for lid removal. $.5 \mathrm{~mm}$ from each lid margin was trimmed and cleaned with sterile saline and ophthalmic ointment was reapplied. Using 7-0 silk, two to three sutures were tied to close the eye the full extent of the eyelids. VetBond cyanoacrylate tissue adhesive (\#1469SB, 3M, St. Paul, MN) was applied to the sutures and the wound to help both hold the sutures in place and keep the eyelids closed for the duration of the monocular deprivation period.

Mice recovered from the anesthesia on a heating pad and were returned to their cages when alert. $4 \mathrm{mg} / \mathrm{kg}$ Ketoprofen was given as a 24 hour analgesic for pain relief. For a period of five days post-suture, the closed eye was checked for both signs of infection and any possible leaks in the sutures or opening in the eyelid. Any potential leaks or openings recorded eliminated the mouse from the study. After five days of monocular deprivation, the mice were anesthetized by the Ketamine and Xyalzine 
mixture in order to prepare for surgical implantation of the recording electrodes. Once completely under deep anesthesia, the sutures were carefully removed from the deprived eye. The eye was then checked under close inspection for any damage to the cornea or corneal opacities.

Visual Evoked Potential Apparatus and Recording

Visual stimuli were produced on a Dell 19-inch flat-screen digital computer monitor and by a computer with an ATI Radeon graphics card. VisionWorks for Electrophysiology (version 1.4.80, Vision Research Graphics, Durham, NH) software was used to create a full-field $1.98 \mathrm{~Hz}$ counterphasing square-wave grating of $100 \%$ contrast at 0.3 cycles/degree spatial frequency, one second per sweep. The visual display was positioned $20 \mathrm{~cm}$ from the front of the eyes of the mouse and was centered on the midline.

Mice were held in place by a custom built restraint system (University of Louisville machine shop) for the recording of visual evoked potentials (VEP). Restraint was needed because all recordings were performed on awake mice, so the device allowed for awake mice to be positioned facing the visual stimulus while also calmed by the small tube space surrounding them. Occasionally a 30 minute acclimation period to the recording apparatus was required the day of or one day post-surgery before initiation of the visual stimulus. Recording were taken from the electrodes through the use of a headstage attached to a differential amplifier (A-M Systems Model 3000, $1 \mathrm{~Hz}$ high pass 
filter, $0.1 \mathrm{kHz}$ low pass filter, Notch $=$ On, Gain $=100 \mathrm{X}$ ). Once habituated, visual stimuli were presented in the following protocol: three recordings of both eyes, three recordings of the eye ipsilateral to the electrodes with the contra eye blocked, six recordings to the contralateral eye with the ipsilateral eye blocked, three recordings of the ipsilateral eye with the contralateral eye blocked again and three recordings of with both eyes blocked or the monitor of the stimulus shut off. Each individual recording was initiated by the $3 \mathrm{mV}$ trigger synchronized with the onset of each stimulus generate by StimulusMaker (version 2.1.35, Vision Research Graphics, Durham, NH) into the oscilloscope which recorded an average for 64 sweeps.

Visual Evoked Potentials Analysis

Data was organized so that the analysis was performed blind to eye, condition and genetic background. Data collected from each saved average for each recording was measured an analyzed using Microsoft Excel, by graphing the data points and collecting the peak to trough voltages. The difference between the recorded peak to trough voltages was recorded as the size of each potential. Averages were taken for each peak to trough difference for every condition, both eyes open, ipsilateral open only, contralateral open only and both eyes blocked. A ratio was formed by averages of contralateral to ipsilateral, allowing for changes across days, animals and conditions to be analyzed. Seen in the results are both representations of the changes that occur across different conditions in both the ratio and the actual differences in the voltages of each average potential. Animals under the same condition were averaged together to provide accurate 
data of comparison across mutant and wildtype mice, and across conditions, normal or monocular deprived. Mice of both 3.5 weeks and 9 weeks of age were compared within each age range.

Latency between initiation of the trigger and the start of the first potential was recorded by measuring the difference between the time of the trigger pulse and the time of the first peak in the VEP. Latency between each VEP peak to peak was recorded as well using the same method of measure time difference. Results of these are found in the Results and Discussion.

\section{Electrode Placement Identification}

Brains of implanted mice were lesioned to verify placement of the electrode into the ideal part of the visual cortex. The mice were anesthetized with $90 \mathrm{mg} / \mathrm{kg}$ Ketamine and $9 \mathrm{mg} / \mathrm{kg}$ Xylazine injection solution, and once under deep anesthesia the recording electrode and indifferent electrode were hooked up to an Isolated Pulse Stimulator (model 2100, A-M Systems, Carlsborg, WA). A .5 $\mu$ Amp negative pulse was applied for a duration of 10 seconds to ensure adequate marking of the recording electrode placement. The mouse was allowed to recover on a heating pad until awake in which they returned to the cage for approximately 24 hours.

After a 24 hour period, the mouse was given a lethal dose of twice the amount of $90 \mathrm{mg} / \mathrm{kg}$ Ketamine and $9 \mathrm{mg} / \mathrm{kg}$ Xylazine mixture. Once the mouse was completely 
under anesthesia, the mouse was restrained with the chest exposed upward. The thoracic cavity was opened by removing approximately $2 \mathrm{~cm}$ by $2 \mathrm{~cm}$ square section of the rib cage. The right atrium was then incised and allowed to bleed out. A PBS $(0.91 \mathrm{NaCl}$ in 0.1 phosphate buffer, $\mathrm{pH}$ 7.4) solution was then inserted via a needle into the left ventricle and the mouse was perfused entirely with PBS. Without allowing any air bubbles into the system, the steady stream of PBS was shut off and a steady stream of paraformaldehyde ( $4 \%$ in PBS) was perfused through the system. After five minutes of adequate perfusion with paraformaldehyde, indicated by the tensing of the skeletal muscles, the head was removed and skull cut away to reveal the brain. The brain from the frontal cortex to the start of the spinal cord was removed completely and placed in a $4 \%$ paraformaldehyde and PBS solution. After overnight post-fix at $4{ }^{\circ} \mathrm{C}$, the brain was then cryoprotected by being inserted for 48 hours at $4^{\circ} \mathrm{C}$ in a $30 \%$ sucrose and PBS solution.

After two days of cryoprotection, the frontal cortex and cerebellum were removed and the cortex including the visual cortex was flash frozen in dry ice and stored at $-80{ }^{\circ} \mathrm{C}$. 40 microns thick slices were cut from the frozen brain by Cryocut 1800 (Reichert-Jung, temperature $=-18^{\circ} \mathrm{C}$ ). The slices were placed in a PBS solution to await slide mounting. The brain slices were mounted on Superfrost/Plus subbed microscope slides for overnight drying. The following protocol was used for the staining of the tissue with Cresyl Violet.

1. Sections were placed in xylene for 3 minutes. 
2. Sections were sequentially rehydrated with ethanol in a series of $100 \%, 95 \%$ and $70 \%$ for 3 minutes each.

3. Sections were rinsed in $\mathrm{ddH}_{2} \mathrm{O}$ for 3 minutes.

4. Sections were then placed in warm $45^{\circ} \mathrm{C}$ Cresyl violet stain $(1 \mathrm{~g}$ Cresyl fast violet in $1000 \mathrm{~mL} \mathrm{ddH} \mathrm{H}_{2} \mathrm{O}$ and $10 \mathrm{~mL} \mathrm{10 \%} \mathrm{acetic} \mathrm{acid)} \mathrm{for} \mathrm{approximately} 30$ seconds or until adequately stained.

5. Sections were rinsed in $\mathrm{ddH}_{2} \mathrm{O}$ to remove excess Cresyl violet.

6. Sections were then dehydrated in sequential series of $70 \%$ ethanol and few drops of glacial acetic acid, $90 \%$ ethanol, and $100 \%$ ethanol for 3 minutes each.

7. Sections were then cover slipped with Permount (Fisher Scientific).

Slide sections were analyzed and the mark from the electrode was identified and pictures were taken. 


\section{RESULTS}

Recordings of 64 one-second sweeps from the oscilloscope were taken and opened on Excel. Individual visual evoked potentials (VEPs) consisted of a set of four peaks, two to each stimulus a sweep, each corresponding to an exact window of time consistent throughout the mouse's groups of VEPs. Peaks were found to be $250 \mathrm{~ms}$ apart measured peak to peak and had a latency observed to be $\sim 120$ ms. Figure 4 shows both the stimulus and response from just the contralateral eye and just the ipsilateral eye from the same mouse. This also sets the normal standard of the contralateral eye maintaining a larger responsiveness when compared to the ipsilateral eye.

\subsection{Week Mice Visual Evoked Potentials}

VEPs recorded in the binocular region following stimulation in both eyes in the wildtype (WT) mice resulted in a group of four peaks found equidistant apart from peak to peak, approximately $250 \mathrm{~ms}$. Each of these peaks along with multiple trials resulted in an average potential size of $.0055 \mathrm{~V}$ uncorrected, observed in Figure 5A. The binocular response was recorded for the wildtype monocular deprived mice and mutant monocular deprived mice. Figure $5 \mathrm{~B}-\mathrm{C}$ also shows the recordings observed when both eyes are blocked and when the stimulus is blocked. No response from the blocked eyes 
Figure 4. This shows the potentials and corresponding stimuli from normal wildtype mice at 3.5 weeks of age, comparing potentials from both the contralateral eye and the ipsilateral eye. A) Shows the contralateral response of a normal wildtype mouse. B) Shows the ipsilateral eye response of a normal wildtype mouse. Four peaks were observed, two corresponding to each phase of the stimulus for the $1.95 \mathrm{~Hz} 1$ second sweep. The latency is observed as $\sim 120 \mathrm{~ms}$ from the start of the trigger to the first peak response. The contralateral eye maintains a rather large response compared to that of the ipsilateral eye. This shows that there is a preferential dominance of the contralateral eye. This eye is therefore the occluded eye in the monocularly deprived mice. 


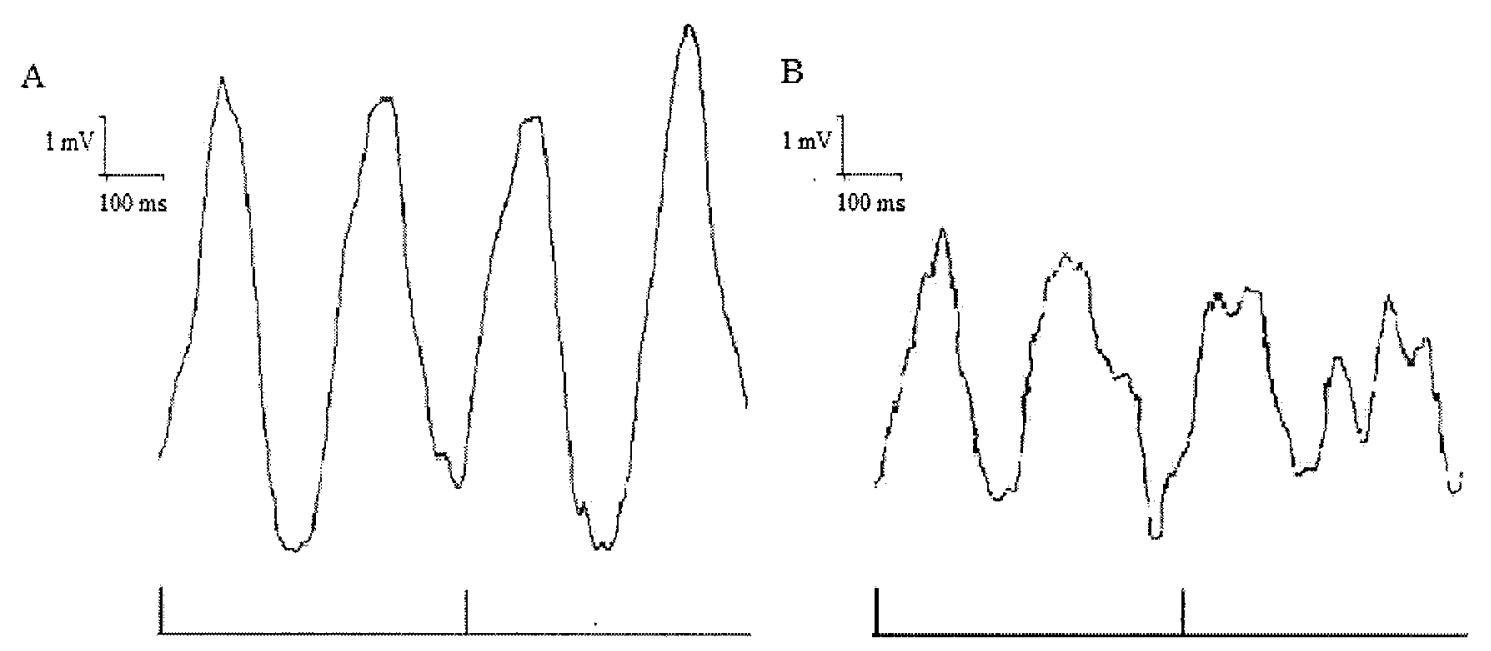

Figure 4 
shows that the method of blocking the eyes were working and the recorded potentials were actually visually evoked. Blocking the stimulus confirms that they were visual evoked potentials and not from any other kind of stimulus.

Figure 6 D-F shows the response of visual stimulus from the eye ipsilateral to the recording electrodes, or the nondeprived eye. WT mice showed an average potential size of $.0045 \mathrm{~V}$ uncorrected in the ipsilateral eye. The response to stimulation stayed fairly consistent as the WT MD showed an average ipsilateral response size of $.0034 \mathrm{~V}$ uncorrected, where the Mt MD showed an average ipsilateral response size of $.0039 \mathrm{~V}$ uncorrected. Figure 6 D-F shows examples of ipsilateral response under each condition compared to their respective contralateral response.

Contralateral response, stimulus shown to the eye contralateral to the recording electrodes or deprived eye, shows the most significant difference when comparing average VEP sizes among different conditions, Figure 6 A-C. WT mice showed an average potential size of $.0063 \mathrm{~V}$ uncorrected, while Mt MD mice showed an average potential size of $.0055 \mathrm{~V}$. While these two potentials appear the same and are relatively the same in comparison (Figure $6 \mathrm{~A}-\mathrm{C}$ ), it is the difference in the WT MD potential compared to the other two conditions. The WT MD showed an average deprived eye potential size of $.0031 \mathrm{~V}$ uncorrected. This is reflected by the potentials seen in Figure 6 A-C, especially when compared to the corresponding ipsilateral responses in Figure 6 DF. 
Figure 5. Visual evoked potentials recorded from a 3.5 week old mouse with both eyes open and both eyes blocked. A) Wildtype normal mouse at 3.5 weeks VEP. B) Wildtype normal mouse at 3.5 weeks VEP with both eyes blocked. C) Wildtype mouse at 3.5 weeks VEP with the stimulus blocked. Four defined visual evoked potentials are observed in the wildtype normal binocular response. There is no visual evoked response with both eyes blocked and with the stimulus blocked. 


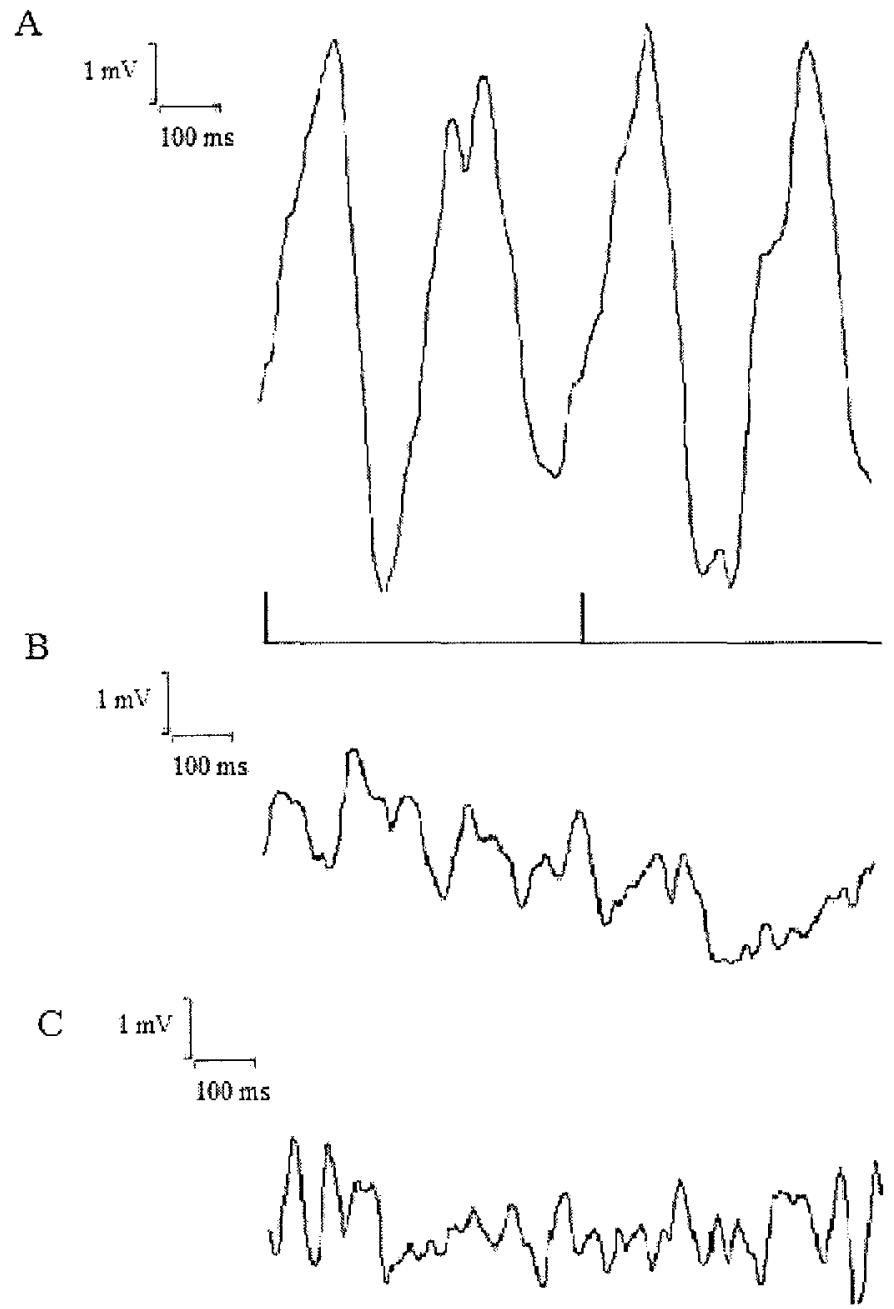

Figure 5 
Figure 6. Visual evoked potentials were recorded with the eye ipsilateral to the electrode placement blocked and the contralateral, dominant, eye open and are shown on the left side. A) Wildtype normal mouse contralateral eye response at 3.5 weeks. B) Wildtype monocular deprived mouse contralateral eye response at 3.5 weeks. C) Mutant monocular deprived mouse contralateral eye response at 3.5 weeks. Contralateral response maintained similar potential sizes with the wildtype normal and mutant monocular deprive mice, but wildtype monocular deprived mice showed a significant decrease in the response size. Visual evoked potentials recorded with the eye contralateral to the electrode placement blocked and the ipsilateral, nondominant, eye open are shown on the right side. D) Wildtype normal mouse ipsilateral response at 3.5 weeks. E) Wildtype monocular deprived mouse ipsilateral response at 3.5 weeks. F) Mutant monocular deprived mouse ipsilateral response at 3.5 weeks age. There was no significant change in the ipsilateral eye's response across each condition, so the same relative size responses were recorded from each. 



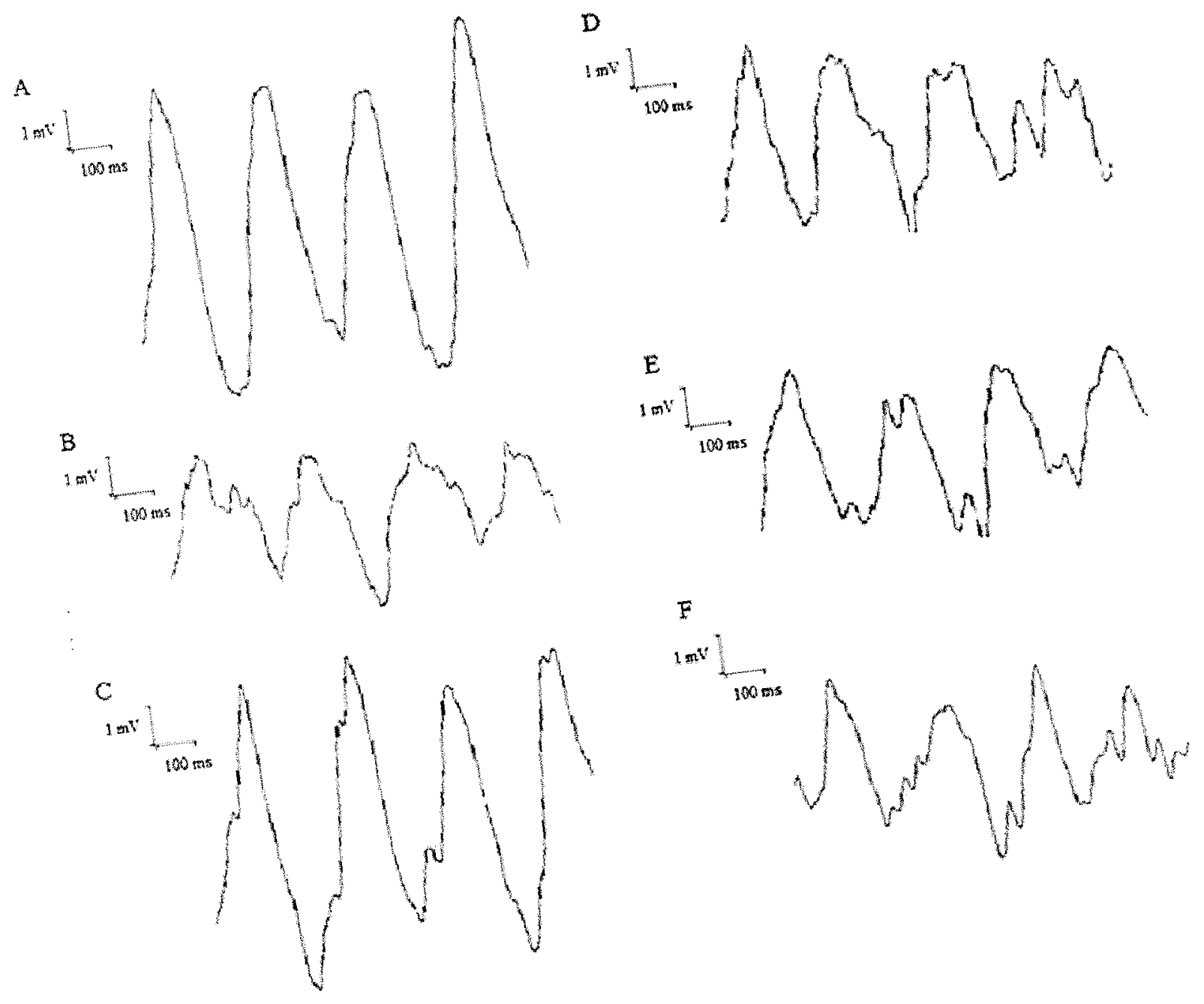

Figure 6 


\subsection{Week Mice Contralateral/Ipsilateral Ratios}

The potential sizes were normalized by eliminating a standard for background noise of approximately $.001 \mathrm{~V}$ uncorrected. This allows for a better analysis of the contralateral to ipsilateral ratio because it does not take into account any parts of the peak that may have been affected by the minute changes in noise level. The ratio of contralateral eye to ipsilateral eye, or deprived eye to nondeprived eye, shows a generalized picture of what is happening with the visual evoked potentials (VEPs) in the different conditions. The normalized ratio of the wildtype mice (WT) shows a contralateral to ipsilateral ration of 1.49 . The normalized ratio of mutant mice (Mt) was found to be 1.57 contralateral to ipsilateral. The mutant monocular deprived ratio (Mt MD) showed a consistent ratio of 1.55 contralateral to ipsilateral. It is in the monocular deprived condition of the wildtype mice (WT MD) that a change can be seen in the contralateral to ipsilateral ratio. The WT MD shows a depressed ratio of 0.87 contralateral to ipsilateral following five days of monocular deprivation. Figure $7 \mathrm{~A}$ expresses that data as a comparison between mice types, wildtype and mutant, and between conditions of the contralateral eye, normal and deprived (MD). While the wildtype shows a depression of the ratio across conditions, the mutant shows relatively no change in the contralateral to ipsilateral ratio. However, analysis of the ratios does not provide a full picture of what is going on in each eye.

\subsection{Week Mice Visual Evoked Potential Contralateral to Ipsilateral Comparisons}


Figure $7 \mathrm{~B}$ shows an analysis of the average visual evoked potentials of contralateral eye compared to ipsilateral eye including standard error across conditions. An ANOVA test was run and shows significance in the Recorded Eye $(\mathrm{F}=8.977, \mathrm{P}=$ $0.005)$ and between the conditions $(\mathrm{F}=4.820, \mathrm{P}=0.007)$. With each mouse condition included, the recorded eye and the condition are both found to be significantly different with a $\mathrm{P}$ value of 0.005 and 0.007 , respectively $(\alpha=0.05)$. Standard error means were calculated for each eye and condition. Mutant normal condition (Mt) had a contralateral standard error of 0.000942 and ipsilateral standard error of 0.000596 . Wildtype normal mice condition (WT) had a contralateral standard error of 0.000504 and ipsilateral of .000504 . Wildtype monocular deprived condition (WT MD) had a contralateral standard error of 0.000596 and ipsilateral of 0.000596 . Mutant monocular deprived condition (Mt MD) had a contralateral standard error of 0.000596 and an ipsilateral standard error of 0.000596 .

Comparisons using a Tukey test of each factor were taken into account for significant differences across conditions. Comparisons by condition within just the contralateral eye show a significant difference between the WT vs. WT MD, with a $\mathrm{P}=$ 0.002. There was also a significant difference between Mt vs. WT MD with $\mathrm{P}=0.033$. Most importantly is that there is significant difference between Mt MD vs. WT MD with a $P$ value of 0.043 . Under the same condition with the only change in condition being the mutation of the knockout of the Munc13-3 gene, there is a significant difference between contralateral eyes. Ipsilateral eyes following the same analytical conditions showed no significant differences across each factor. 
Figure 7. Shows the normalized ratio across all conditions compared to the uncorrected visual evoked potential recordings from each eye between conditions at 3.5 weeks of age. A) Shows the contralateral to ipsilateral normalized ratio for the wildtype normal, wildtype monocular deprived and mutant monocular deprived mice. A significant decrease in the contralateral to ipsilateral ratio was observed in the wildtype monocular deprived mice. B) Shows the average contralateral VEP amplitude and the average ipsilateral VEP amplitude, including standard error, for mutant normal ( $\mathrm{n}=2)$, wildtype normal $(\mathrm{n}=5)$, wildtype monocular deprived $(\mathrm{n}=5)$ and mutant monocular deprived mice $(n=5)$. A large average contralateral response is observed in all conditions except for the significant decrease in contralateral potential size found in the wildtype monocular deprived mice. Ipsilateral response average remained consistent across each condition. Asterisk $(*)$ indicates significance. 


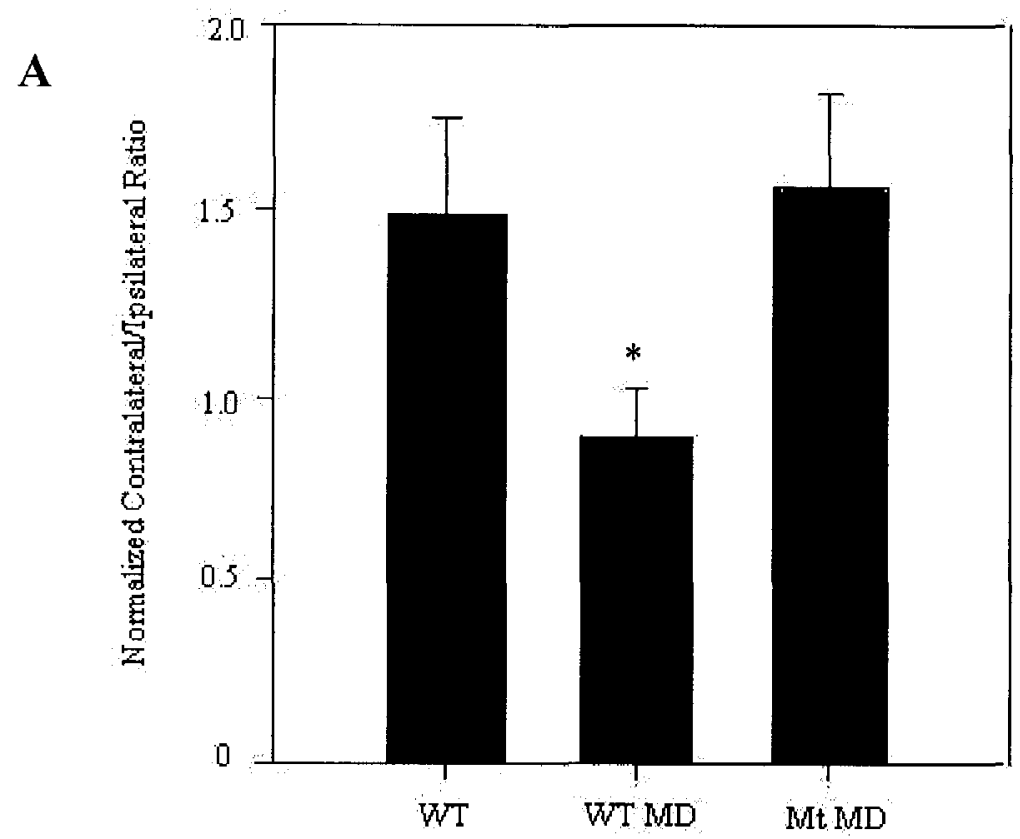

B

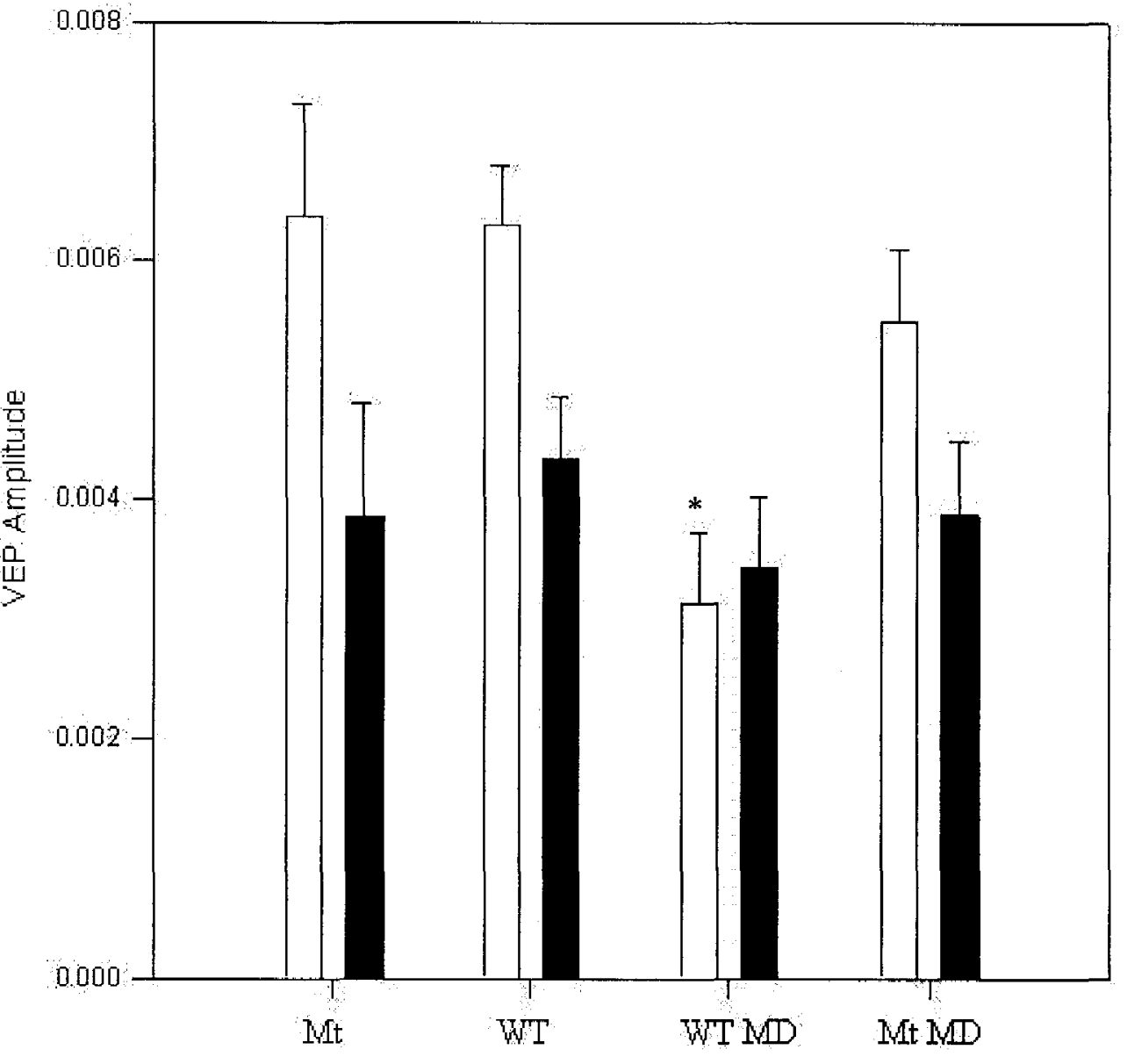

Recorded Eye $x$ Condition

Figure 7 
Analysis of the data found significantly different through the Tukey test and the raw data plus standard error found in the graph allows for insight into the mechanism of what is causing the depression of the contralateral to ipsilateral ratio in the WT MD. While the wildtype normal condition expresses a larger contralateral response compared to ipsilateral response, the effect of five day monocular deprivation to the normal wildtype mice does not cause an increase in responsiveness of the ipsilateral eye, but a depression in responsiveness of the contralateral deprived eye. This is consistent with the results found from previous research of monocular deprivation of young mice seen in Figure 2 (Frenkel and Bear, 2004). However, the same monocular deprivation does not have the same effect on the mice with the mutation of the Munc13-3 gene.

\section{Week Mice Visual Evoked Potentials}

Visual evoked potentials for mice reared to 9 weeks of age before implantation of recording electrodes and monocular deprivation were recorded and collected for blind analysis. Potentials were recorded for the same protocol as the 3.5 week mice and under all of the same conditions. Binocular responses were recorded from each condition providing a baseline of analysis. Recordings from both eyes open in the 9 week wildtype mice (WT) had an average potential size of $0.0048 \mathrm{~V}$ uncorrected, example shown in Figure 9. Recordings from the animal with both eyes closed showed no evoked potentials and a relatively smooth baseline. Recordings were done with the stimulus off, no visual stimulus present shows no responses observed in the recordings; therefore the visual stimulus was responsible for the potentials recorded. 
Figure 8. This shows the potentials and corresponding stimuli from normal wildtype mice at 9 weeks of age, comparing potentials from both the contralateral eye and the ipsilateral eye. A) Shows the contralateral response of a normal wildtype mouse. B) Shows the ipsilateral eye response of a normal wildtype mouse. Four peaks were observed, two corresponding to each input of the stimulus for the $1.95 \mathrm{~Hz}$ sweep. The latency is observed as $\sim 120 \mathrm{~ms}$ from the start of the trigger to the first peak response. The contralateral eye maintains a rather large response compared to that of the ipsilateral eye. This shows that there is a preferential dominance of the contralateral eye. This eye is the occluded eye in the monocular deprived mice. 


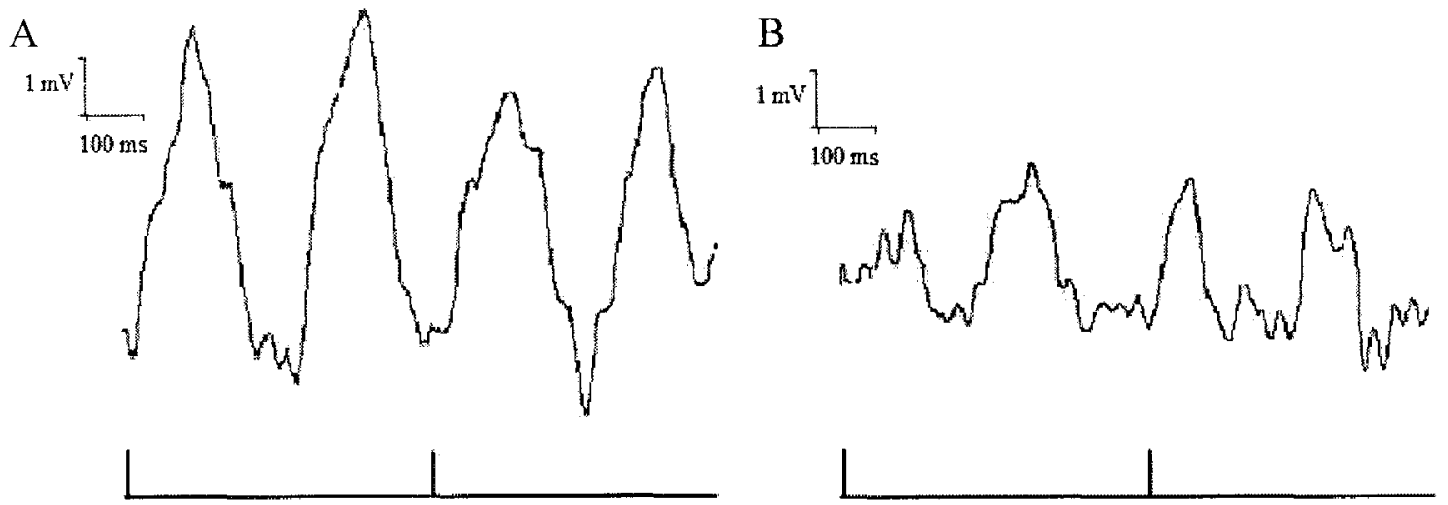

Figure 8 
Responses recorded from the ipsilateral eye, eye on the same side as the electrode implantation, are found under each condition in Figure 10 D-F. Average uncorrected responses ipsilateral eye for WT and WT MD are $0.0034 \mathrm{~V}$ and $0.0047 \mathrm{~V}$, respectively. Average uncorrected responses in the ipsilateral eye for Mt and Mt MD are 0.004 and 0.004 , respectively.

Contralateral, or deprived eye, responses are seen in Figure 10 A-C. Average response sizes of VEPs recorded from just the contralateral eye in WT and WT MD are $0.0049 \mathrm{~V}$ and $0.0041 \mathrm{~V}$, respectively. Responses from the contralateral eye in Mt and Mt MD had an average potential size of $0.0052 \mathrm{~V}$ and $0.0049 \mathrm{~V}$, respectively. Examples comparing relative VEP size for the contralateral eye to the ipsilateral eye are found in Figure 10. VEPs shown are those reflective of the averages shown, not averages themselves. They are actually individual recordings of mice used to measure potential size that factor into the average VEP sizes.

\section{Week Mice Contralateral/Ipsilateral Ratios}

Using the same normalization, the ratios of the 9 week contralateral eye to ipsilateral eye potential sizes were found for each of the factors, wildtype (WT), mutant (Mt), wildtype monocular deprive (WT MD) and mutant monocular deprived (Mt MD). The ratios were plotted in Figure 11A comparing the animal type, mutant and wildtype, between conditions, normal versus deprived. WT contralateral to ipsilateral was found to be 1.59 and Mt contralateral to ipsilateral was found to be 1.56 . 
Figure 9. Binocular visual evoked potentials recorded from a 9 week old mouse with both eyes open, both eyes blocked and the stimulus blocked. A) Wildtype normal mouse binocular response at 9 weeks. B) Wildtype normal mouse at 9 weeks VEP with both eyes blocked. C) Wildtype normal mouse at 9 weeks VEP with the stimulus blocked. Binocular VEP response from both eyes open shows four peaks $\sim 250 \mathrm{~ms}$ apart. The recording with both eyes blocked shows no corresponding peaks to the stimulus, showing that our eye blocks worked. The stimulus off shows that there is no response or waveform created from any other source, so the potentials recorded must be visually evoked. 


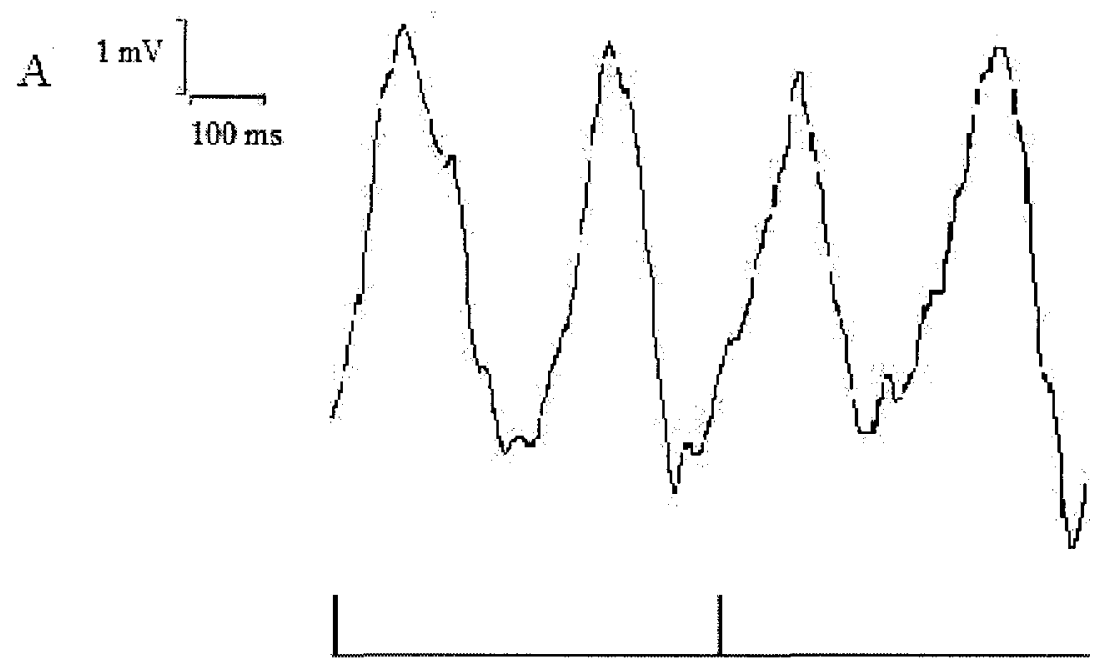

B $\quad 1 \mathrm{mV}]_{100 \mathrm{~ms}}$

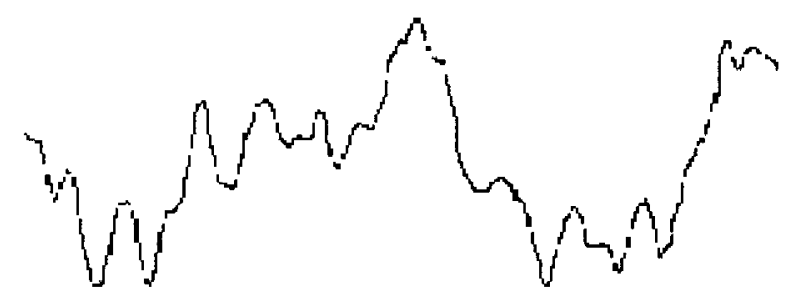

C $1 \mathrm{mV}]_{100 \mathrm{~ms}}$

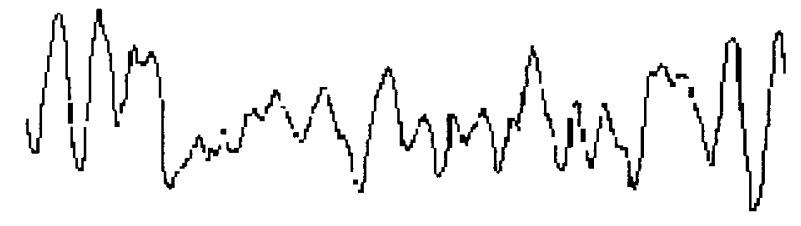

Figure 9 
Figure 10. Visual evoked potentials were recorded with the eye ipsilateral to the electrode placement blocked and the contralateral, dominant, eye open in 9 week old mice. A) Wildtype normal mouse contralateral eye response at 9 weeks. B) Wildtype monocular deprived mouse contralateral eye response at 9 weeks. C) Mutant monocular deprived mouse contralateral eye response at 9 weeks. Contralateral response maintained similar potential sizes throughout all conditions at 9 weeks age. Contralateral responses were larger than ipsilateral responses except in monocularly deprived wildtype mice. Visual evoked potentials were recorded with the eye contralateral to the electrode placement blocked and the ipsilateral, nondominant, eye open. D) Wildtype normal mouse ipsilateral response at 9 weeks. E) Wildtype monocular deprived mouse ipsilateral response at 9 weeks. F) Mutant monocular deprived mouse ipsilateral response at 9 weeks age. There was a significant increase in the ipsilateral response of the wildtype monocular deprived mice compared to the wildtype normal and mutant monocular deprived mice. Compared to the contralateral responses, the ipsilateral response were smaller in both the WT and Mt MD, but increased significantly larger than the contralateral response in the WT MD mice. 


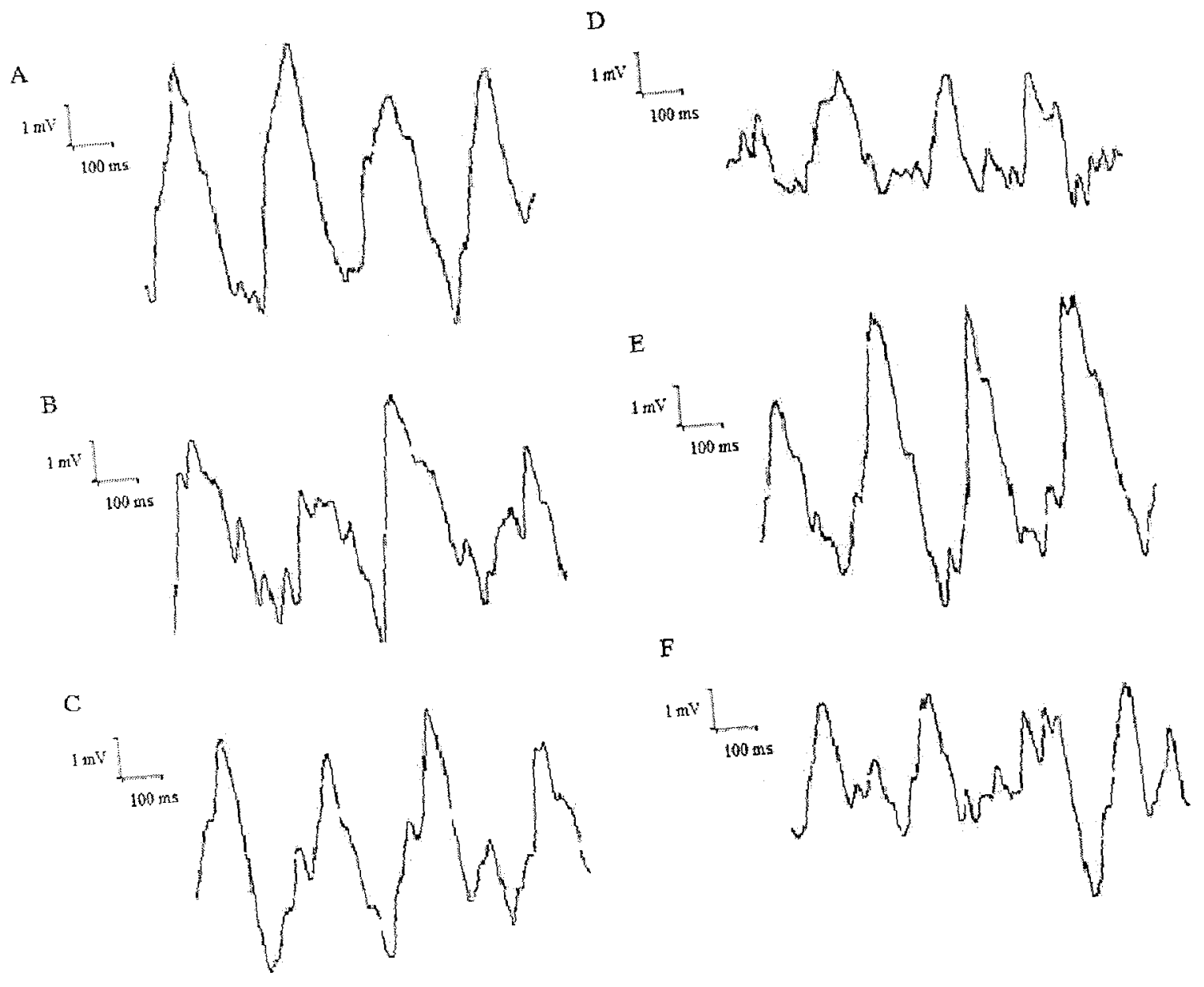

Figure 10 
Changing from normal to monocularly deprived, the WT MD ratio was 0.84 and the Mt MD ratio was 1.26. Figure 11A shows a large decrease across conditions for the wildtype mice and a mild decrease across conditions for the mutant mice.

9 Week Mice Visual Evoked Potential Contralateral to Ipsilateral Comparisons

Figure 11B shows the average values including standard error for the eye contralateral, or deprived eye, to the electrode implant and ipsilateral to the electrode implant recorded from each within each condition. Each condition was tested for significant difference with $\alpha=0.05$. An ANOVA test was run and found significance in the Recorded Eye $(\mathrm{F}=5.014, \mathrm{P}=0.034)$ and between the Recorded Eye $\mathrm{x}$ Condition $(\mathrm{F}=$ $4.331, \mathrm{P}=0.013)$. Over all conditions there was a significant difference found between recorded eye (Tukey, $\mathrm{P}=0.034, \alpha=0.05$ ) and the differing levels of the recorded eye were found to be dependent upon what condition was present (Tukey, $\mathrm{P}=0.013, \alpha=$ 0.05). Standard errors were recorded for each of the recorded eyes resulting in Mt contralateral eye 0.000663 , Mt ipsilateral eye 0.000663 , WT contralateral eye 0.000271 , WT ipsilateral eye 0.000271, WT MD contralateral 0.000297, WT MD ipsilateral 0.000297, Mt MD contralateral 0.000297 and Mt MD ipsilateral 0.000297.

Comparisons of the contralateral eye between conditions revealed no significant difference between all conditions, mutant (Mt), wildtype (WT), wildtype monocular deprived (WT MD) and mutant monocular deprived (Mt MD). Comparisons between the 
Figure 11. Shows the normalized ratio across all conditions compared to the uncorrected visual evoked potential recordings from each eye between conditions at 9 weeks of age. A) Shows the contralateral to ipsilateral normalized ratio for the wildtype normal, wildtype monocular deprived and mutant monocular deprived mice. A significant decrease in the contralateral to ipsilateral ratio was observed in the wildtype monocular deprived mice. B) Shows the average contralateral VEP amplitude and the average ipsilateral VEP amplitude, including standard error, for mutant normal $(n=1)$, wildtype normal $(\mathrm{n}=5)$, wildtype monocular deprived $(\mathrm{n}=5)$ and mutant monocular deprived mice $(n=5)$. A large average contralateral response is observed in all conditions. Ipsilateral response average significantly increased in the wildtype monocular deprived mice, and remained consistently smaller in all other conditions. Asterisk $\left({ }^{*}\right)$ indicates significant difference. 

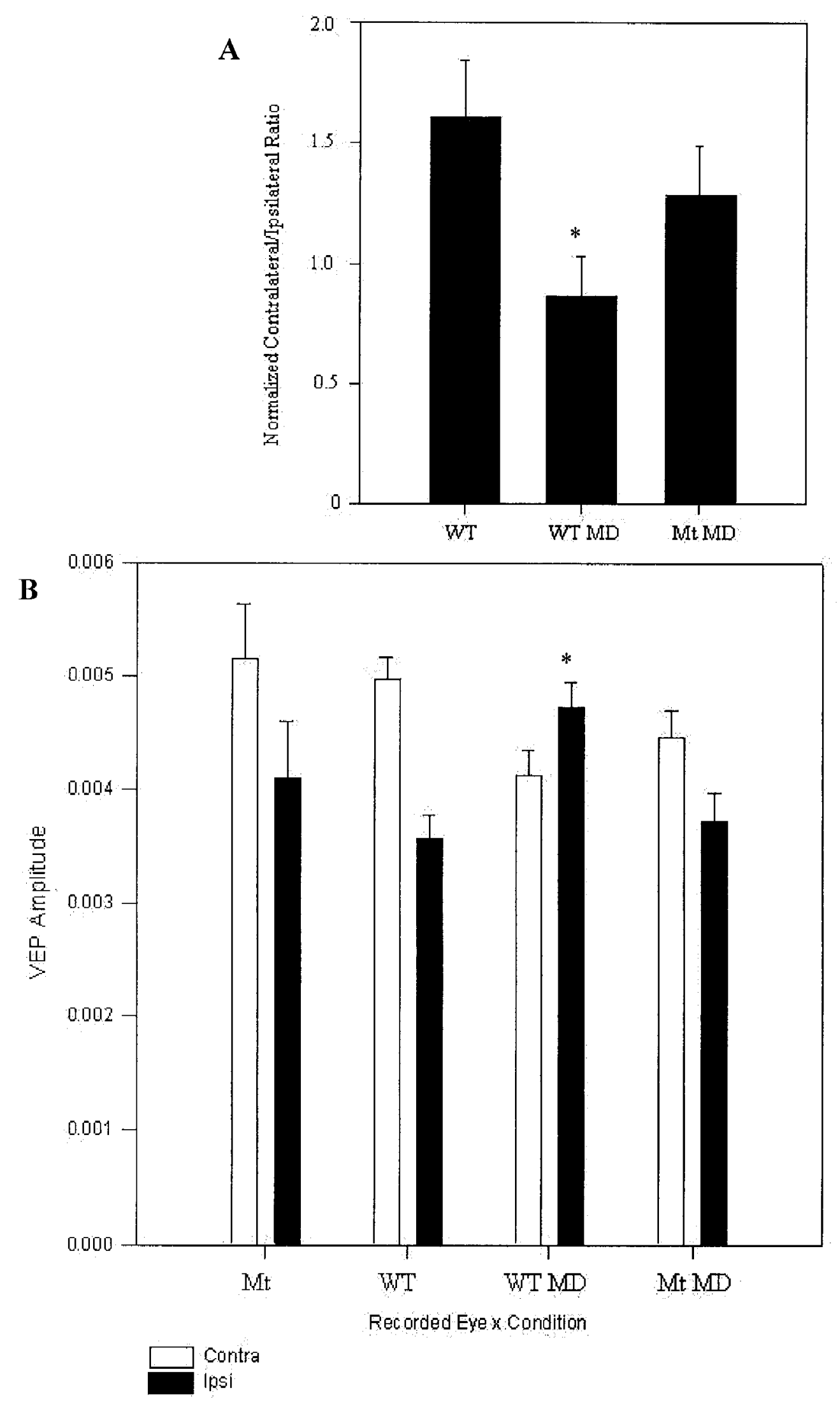

Figure 11 
ipsilateral eye did show a significant difference between the WT and WT MD mice (Tukey, $\mathrm{P}=0.004$ ). A comparison between the ipsilateral eyes of the Mt MD and the WT and Mt mice revealed no significant differences in VEP amplitude. The comparison of ipsilateral eye VEPs between the WT MD and Mt MD revealed that there is a significant difference (Tukey, $\mathrm{P}=0.028$ ). The deprived eye therefore remains consistent throughout monocular deprivation and has no significant change in the VEP size. The open eye, ipsilateral, has a marked increase response in the WT MD mice. The Mt MD mice do not have any significant difference in the potentials of either eye from the WT mice, so the mutation causes no effect from MD.

\section{Latency, Impedance and Electrode Lesion}

The latency between the trigger and the initial evoked potential was measured through randomly selected potentials across every set of conditions. The response to the trigger initiated on average of $120 \mathrm{~ms}$ with no significant difference between conditions. More importantly is the measurement of time between the peaks of the visual evoked potentials. Each potential was on average $250 \mathrm{~ms}$ apart, making for four peaks consistently spaced $250 \mathrm{~ms}$ from each, responding at the exact same point across trials and animals. This allowed for consistent measurement of only visual evoked potentials responding directly to the stimuli. Figure 4 shows the stimulus and the corresponding peaks for 3.5 week old mice and Figure 8 shows the stimulus and the corresponding peaks for 9 week old mice. 
Figure 12. A period of three days of measurement was used for analysis of recovery of wildtype monocular deprived mice. The figure shows an increase in the contralateral to ipsilateral ratio of the wildtype monocular deprived mice indicating its slow progression towards the wildtype normal ratio. 


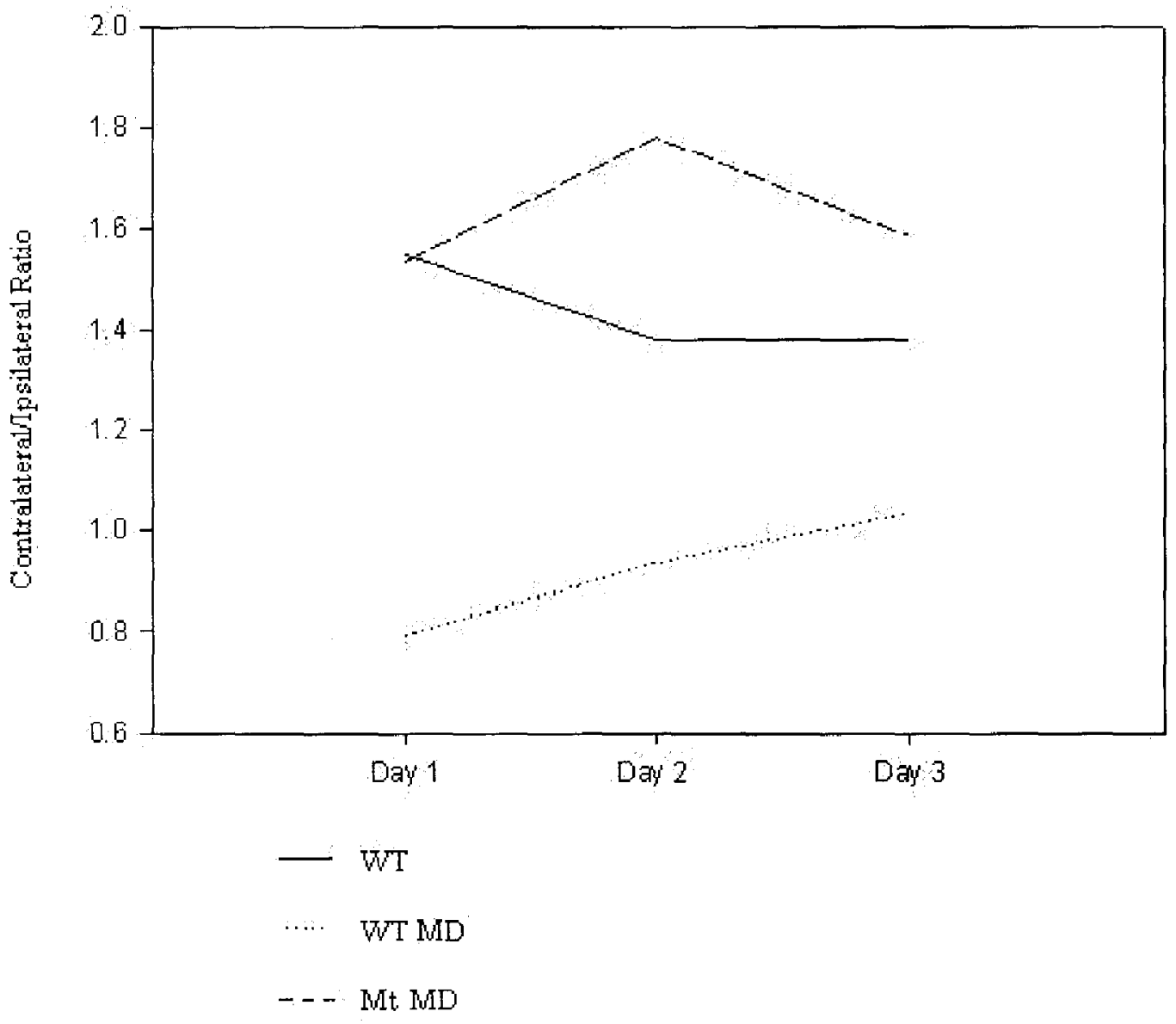

Figure 12 
Impedance was measured for each recording electrode implanted and yielded no significant effect on the size of the potentials being recorded. Impedances averaged between $Z=0.34$ to $Z=0.48$.

Figure 13 shows the exact position of an electrode placement. Placement was approximately $450 \mu \mathrm{m}$ into the visual cortex binocular region, at around the levels of layers IV and V. 
Figure 13. An image was taken of the marked left by the recording electrode after completion of the lesion and staining procedure. The picture shows the electrode placement in the binocular region of the visual cortex, indicating ideal placement. A) The depth of the electrode is shown by the lesion. The depth shows electrode placement in-between layers IV and V. B) The electrodes entry point and placement is identified in this section. C) An image of the mouse brain showing the labeled areas of the visual cortex and hippocampus (Capra, 2010). 


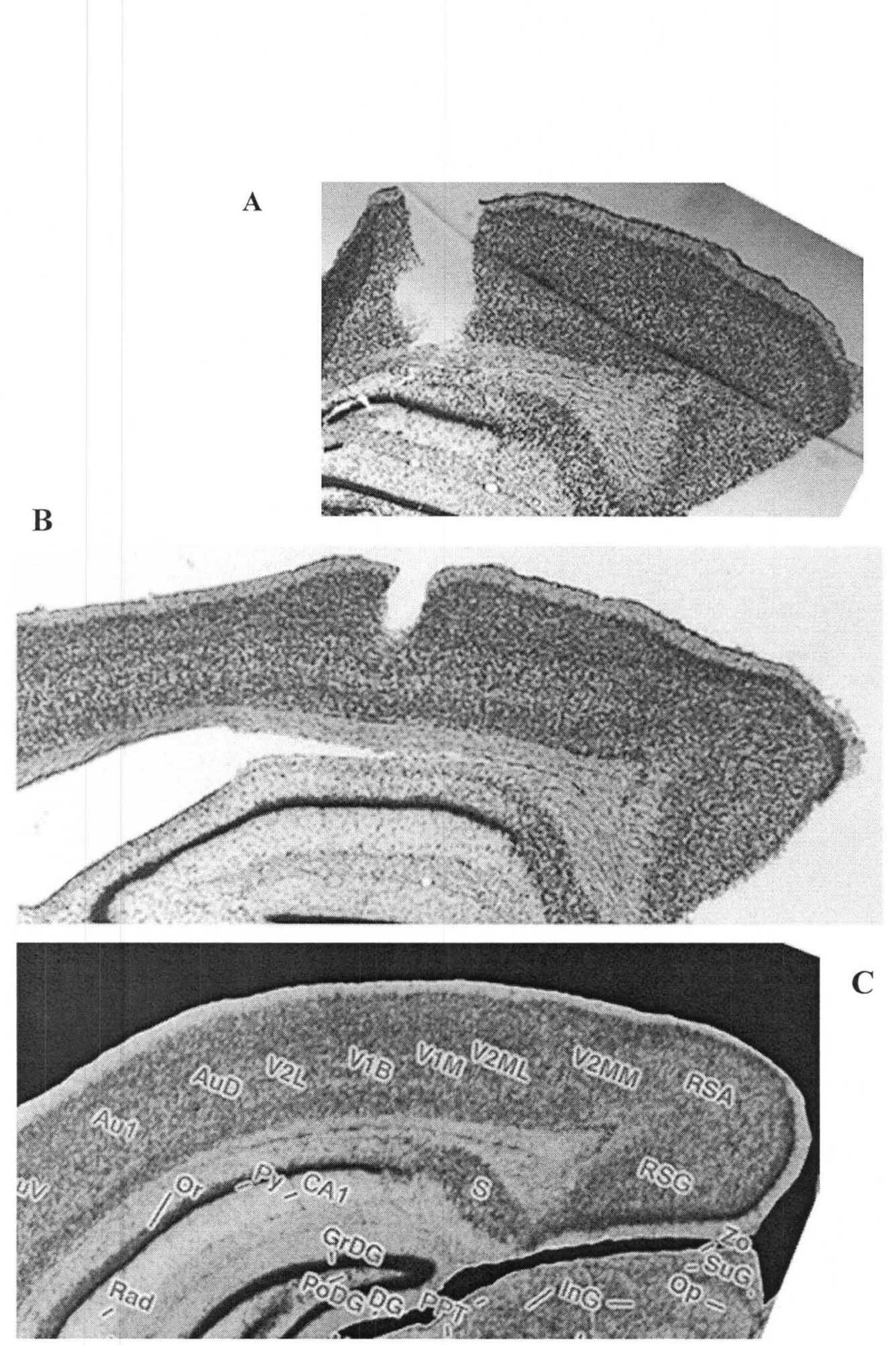

Figure 13

(Capra, 2010) 


\section{DISCUSSION}

Summary of Results

Analysis of the effects of monocular deprivation of mice, not including the mutant Munc13-3 knockout, first shows replication of the results evidenced by Sawtell et al., 2003. Monocular deprivation of mice 3.5 weeks of age for five days causes no change in the nondeprived ipsilateral eye, but causes a significant decrease in the response of the deprived contralateral eye. 3.5 week old mutant mice lacking the Munc13-3 gene showed no effect of monocular deprivation, yielding no significant difference from the wildtype normal mice, but had a significantly larger deprived contralateral response compared to the wildtype monocular deprived response. In 9 week old mice, monocular deprivation effects shift in the wildtype monocular deprived mice. The wildtype maintains the same potential pattern of large contralateral eye response and small ipsilateral eye response. Monocular deprivation causes no significant decrease in the deprived contralateral eye, but instead caused a significant increase in responsiveness to the ipsilateral nondeprived eye, again showing similar results seen in Figure 2 (Sawtell et al., 2003). The knockout Munc13-3 mutant mice at 9 weeks yielded no significant difference to the wildtype normal mice, yet revealed a significantly smaller ipsilateral eye response when compared to the wildtype monocular deprived response. 
After even a period a three days, an increase in the contralateral to ipsilateral ratio for the monocular deprived mice was seen, indicating recovery begins to occur almost immediately after the first day of recording. This provided important insight in that the monocular deprivation after an extended period of exposure will correct itself and that when analyzing results from future monocular deprivation studies, it is important to note that recovery does occur, so the initial effects of monocular deprivation must be recorded soon after the opening of the deprived eyes. The latency between peak to peak also is necessary to remain consistent depending upon the trigger frequency used. In this case, the trigger used was $1.95 \mathrm{~Hz}$, or two shifts in the stimulus grating per second, which if they are visual evoked potentials, there should be four total responses corresponding to each change in the stimulus. Because the stimuli are spaced a $500 \mathrm{~ms}$ apart it is necessary that after the set latency of that mouse that each peak correspond $250 \mathrm{~ms}$ equidistant apart. Any variation means that the response is not synchronized to the change in the visual stimulus, so the resultant peaks are not visual evoked potentials. As seen in the results, the measurement between each peak was recorded approximately 250 ms apart from one another. Latency from the initiation of the trigger to that of the response was recorded from each animal and averaged around $120 \mathrm{~ms}$ apart and remained relatively consistent across most animals.

\section{Munc13-3 Neuronal Plasticity}

Evidence from this research shows that the Munc13-3 gene does play a significant role in plasticity of the visual cortex as evidenced using the classic monocular deprivation 
model. Mice lacking the Munc13-3 gene cause an elimination of any kind of synaptic change or response in the visual cortex during a period of monocular deprivation, as evidenced by no change in the potential response compared to the wildtype normal mice. Although it does not point to any mechanism specific, it does warrant further analysis of the Munc13-3 genes role in visual plasticity. Monocular deprivation over an extended period of time causes a shift in the visual responsiveness. In young mice, the rewiring causes the responsiveness of the dominate eye of the cortex to decrease due to deprivation. In older mice, the maintained plasticity allows for an increased responsiveness of the nondeprived eye, while maintaining the responsiveness of the deprived eye.

Munc13-3 is part of the unc-13 gene family which is involved in exocytosis and neurotransmitter release (Brose et al., 1995; Betz et al., 1997; Augustin et al., 1999a; Basu et al., 2007). Expression of the gene remains low prenatally, but shows an increase in expression through day 22 postnatally. All evidence points to Munc13-3 being related to synaptic short-term synaptic plasticity, so it is not far reached to assume that its expression in the visual cortex relates to synaptic plasticity from monocular deprivation (Zucker, 1989; Augustin et al., 2001; Junge et al., 2004; Zikich et al., 2008; Shin et al., 2010). The Munc13-1 isoform is present in nearly all of the brain regions, where as Munc13-2 is expressed mostly in the rostral cortex and Munc13-3 are found to be expressed mostly in the caudal brain regions (Augustin et al., 1999b; Yang et al., 2002). Most research indicates that all isoforms of Munc13 involve short-term synaptic plasticity by using $\mathrm{Ca}^{2+}$ binding sites to reduce synaptic depression (Shin et al., 2010). 
Munc13-3 has mostly been studied in the cerebellum where Munc13-3 mutants tend to show reduced neurotransmitter release probability suggesting that the gene itself acts to reduce synaptic plasticity in the cerebellum (Augustin et al., 2001; Zucker, 1989). Because the Munc13-3 gene causes decreased paired pulse facilitation, and mutation BDNF, a neuronal plasticity promoter, which results in decreased paired pulse facilitation in the cerebellum, it is reasonable to assume that the Munc13-3 gene serves to decrease synaptic plasticity of the cerebellum (Augustin et al., 2001; Berardi and Maffei, 1999). Identification of Munc13-3 as part of the plasticity gene model showed relative expressions of Munc13-3 mRNA in the visual cortex to have exactly the opposite levels of expression suggested for a plasticity gene in relation to dark rearing, normal expression low at 3.5 weeks and high at 9.5 and dark-reared expression high at 3.5 and low at 9.5 weeks. This pattern follows the "anti-plasticity" gene level of expression (Yang et al., 2002; Yang et al., 2007).

Electrophysiological analysis resulted in a slightly different categorical understanding of the Munc13-3 gene than merely being an "anti-plasticity" gene in the visual cortex. The "anti-plasticity" model would suggest that at the lower expression of the gene at 3 weeks of age, a mutation would cause plasticity to occur. However, the results indicate a complete eradication of any form of plastic changes in the mutation when compared to a normal monocularly deprived mouse. At 9 weeks of age, the same effect happens, where the monocular deprivation effect is lost due to the mutation loss of Munc13-3 gene. This confirms that the Munc13-3 gene is involved in plasticity of the 
visual cortex; however, it suggests that the gene is necessary to work in conjunction with other plasticity genes to regulate, promote or inhibit plasticity in the visual cortex. As a gene that is involved in synaptic release and transmission, Munc13-3 mutation prevents plasticity of the critical period from occurring.

Visual Evoked Potentials and Monocular Deprivation Difficulties

Several sets of obstacles had to be overcome or are still present in the following protocol for the recording of visual evoked potentials. The first primary issue encountered was the successful recording of VEP potentials. Slight modifications were made, such as encompassing the entire recording electrode wire in the glue before use of the dental acrylic. Doing so allowed for visual evoked potentials to have much less interference and noise in the recordings.

Another issue arose with the development and utilization of the monocular deprivation technique. Occasionally monocular deprived mice would be able to remove the sutures and scratch off any glue present, open the deprived eye earlier, thus completely eliminating it from the experiment. Also, even with protective layers of ophthalmic ointment applied, there were still occasional corneal opacities, eliminating those mice from the study.

After the completion of the surgical implantation of the electrodes, another issue arose that still is an issue today. After an extended period of time, most of the mice with 
the surgery will have lost the 'head caps' causing any extended analysis throughout the lifespan to become unpredictable as to whether the head cap and recording electrode positions would be maintained. Several mice maintain the head cap for periods of several months, where many others would lose the head cap within a matter of a couple weeks or less, even with the same protocol being maintained across each successful and unsuccessful group. This made it necessary to compare groups of like animals instead of being able to compare the mouse's monocular deprivation effect compared to its own initial potentials. Although attempted at several times, successful integration of implantation and recording, monocular deprivation and opening must have caused loosening of the head cap because this was never completed in its entirety.

The trigger was one of the biggest problems because it caused for groups of data to be thrown out dude to a loss of potential because the trigger was not synchronizing with the visual stimulus. Using a photocell trigger that responds to the stimulus directly, a nine volt response to the stimulus was produced, allowing for potentials to be recorded and synchronized to the trigger. To help find a solution for the computer trigger, the software programmer of the trigger computer program was contacted and the program went through multiple versions to fix this synchronization issue that was causing the averaging and loss of potentials. The new computer trigger works successfully and allows for a consistent latency between the trigger and recorded response with no loss due to synchronization.

\section{Future Directions}


The first step of future research would be to continue to study the monocular deprivation of the Munc13-3 mutant knockout by doing lifespan comparisons within mice. This would require a decent amount of mice because of issues involving loss of head caps that can occur; however, it would be interesting to see the effects of monocular deprivation comparing the mice's initial recordings, recordings from the open eye throughout the monocular deprivation and recordings of the monocular deprivation effect when the eye is opened. Further analysis could be done of the recovery period by performing extended recordings of the subsequent weeks following monocular deprivation to note the period of time and the level of recovery noted.

The main goal of future research is to apply the same experiment methods used for the two ages of Munc13-3 mice towards the already available Dab-1 mice currently used in Dr. Mower's lab. The Dab-1 gene has been identified and implicated to be gene that contributes towards plasticity (Yang et al., 2006) and electrophysiological monocular deprivation studies of the Dab-1 gene knockout mutant should be studied to see its effect as well. Protein analysis of the Dab-1 gene suggests that the expression at 3.5 and 9.5 weeks both normal and dark-reared result in an expression of large peak at 3.5 week and nadir at 9.5 weeks normal expression and reversed for delay due to dark-rearing. This bidirectional regulation suggests that Dab-1 follows the "plasticity" pattern of expression in the visual cortex. Dark-rearing slows the course of time of the critical period and the regulatory genes involved within this plasticity are identifiable via this method (Yang et al., 2006). It is this evidence that Dab-1 correlates with post-natal plasticity that makes it an ideal candidate to see if expression occurs physiologically through monocular 
deprivation electrophysiological studies of both normal and mutant Dab-1 expressed mice.

Finding viable knockout mice of other identified candidates for plasticity of the visual system is another necessary step. The unfortunate part is there is limited availability of mice knockout mutants of these genes and many of them do not produce survivable mice. Overcoming this obstacle is necessary to find the physiological effects of monocular deprivation on the visual system and what genes regulate or modify the plastic response to such conditions. 


\section{REFERENCES}

Augustin I, Rosenmund C, Sudhof TC, Brose N (1999a) Munc13-1 is essential for fusion competence of glutamatergic synaptic vesicles. Nature 400:457-461.

Augustin I, Betz A, Herrmann C, Jo T, Brose N (1999b) Differential expression of two novel Munc13 proteins in rat brain. Biochem J 337 ( Pt 3):363-371.

Augustin I, Korte S, Rickmann M, Kretzschmar HA, Sudhof TC, Herms JW, Brose N (2001) The cerebellum-specific Munc13 isoform Munc13-3 regulates cerebellar synaptic transmission and motor learning in mice. J Neurosci 21:10-17.

Basu J, Betz A, Brose N, Rosenmund C (2007) Munc13-1 C1 domain activation lowers the energy barrier for synaptic vesicle fusion. J Neurosci 27:1200-1210.

Berardi N, Maffei L (1999) From visual experience to visual function: roles of neurotrophins. J Neurobiol 41:119-126.

Betz A, Okamoto M, Benseler F, Brose N (1997) Direct interaction of the rat unc-13 homologue Munc13-1 with the $\mathrm{N}$ terminus of syntaxin. J Biol Chem 272:25202526.

Brose N, Hofmann K, Hata Y, Sudhof TC (1995) Mammalian homologues of Caenorhabditis elegans unc-13 gene define novel family of C2-domain proteins. $J$ Biol Chem 270:25273-25280.

Capra T (2010) Mouse Brain Library. In, p mbl.org: Neurogenetics at UT Health Science Center.

Cho KK, Khibnik L, Philpot BD, Bear MF (2009) The ratio of NR2A/B NMDA receptor subunits determines the qualities of ocular dominance plasticity in visual cortex. Proc Natl Acad Sci U S A 106:5377-5382.

Cragg BG (1975) The development of synapses in kitten visual cortex during visual deprivation. Exp Neurol 46:445-451.

Crair MC, Horton JC, Antonini A, Stryker MP (2001) Emergence of ocular dominance columns in cat visual cortex by 2 weeks of age. J Comp Neurol 430:235-249. 
Cynader M, Mitchell DE (1980) Prolonged sensitivity to monocular deprivation in darkreared cats. J Neurophysiol 43:1026-1040.

Daw NW, Fox K, Sato H, Czepita D (1992) Critical period for monocular deprivation in the cat visual cortex. J Neurophysiol 67:197-202.

Garey LJ (1971) A light and electron microscopic study of the visual cortex of the cat and monkey. Proc R Soc Lond B Biol Sci 179:21-40.

Garey LJ, Powell TP (1971) An experimental study of the termination of the lateral geniculo-cortical pathway in the cat and monkey. Proc R Soc Lond B Biol Sci 179:41-63.

Gilbert CD, Wiesel TN (1979) Morphology and intracortical projections of functionally characterised neurones in the cat visual cortex. Nature 280:120-125.

Guire ES, Lickey ME, Gordon B (1999) Critical period for the monocular deprivation effect in rats: assessment with sweep visually evoked potentials. J Neurophysiol 81:121-128.

Hubel DH, Wiesel TN (1970) The period of susceptibility to the physiological effects of unilateral eye closure in kittens. J Physiol 206:419-436.

Hubel DH, Wiesel TN (1972) Laminar and columnar distribution of geniculo-cortical fibers in the macaque monkey. J Comp Neurol 146:421-450.

Hubel DH, Wiesel TN, LeVay S (1977) Plasticity of ocular dominance columns in monkey striate cortex. Philos Trans R Soc Lond B Biol Sci 278:377-409.

Junge HJ, Rhee JS, Jahn O, Varoqueaux F, Spiess J, Waxham MN, Rosenmund C, Brose $\mathrm{N}$ (2004) Calmodulin and Munc 13 form a Ca2+ sensor/effector complex that controls short-term synaptic plasticity. Cell 118:389-401.

LeVay S, Stryker MP, Shatz CJ (1978) Ocular dominance columns and their development in layer IV of the cat's visual cortex: a quantitative study. J Comp Neurol 179:223-244.

LeVay S, Wiesel TN, Hubel DH (1980) The development of ocular dominance columns in normal and visually deprived monkeys. J Comp Neurol 191:1-51.

Lowel S, Singer W (1987) The pattern of ocular dominance columns in flat-mounts of the cat visual cortex. Exp Brain Res 68:661-666.

Lund JS, Lund RD, Hendrickson AE, Bunt AH, Fuchs AF (1975) The origin of efferent pathways from the primary visual cortex, area 17, of the macaque monkey as 
shown by retrograde transport of horseradish peroxidase. J Comp Neurol $164: 287-303$.

Mitchell DE (1988) The extent of visual recovery from early monocular or binocular visual deprivation in kittens. J Physiol 395:639-660.

Mower GD (1991) The effect of dark rearing on the time course of the critical period in cat visual cortex. Brain Res Dev Brain Res 58:151-158.

Mower GD, Christen WG (1985) Role of visual experience in activating critical period in cat visual cortex. J Neurophysiol 53:572-589.

Mower GD, Berry D, Burchfiel JL, Duffy FH (1981) Comparison of the effects of dark rearing and binocular suture on development and plasticity of cat visual cortex. Brain Res 220:255-267.

Mower GD, Caplan CJ, Christen WG, Duffy FH (1985) Dark rearing prolongs physiological but not anatomical plasticity of the cat visual cortex. J Comp Neurol $235: 448-466$.

Olson CR, Freeman RD (1980) Profile of the sensitive period for monocular deprivation in kittens. Exp Brain Res 39:17-21.

Sawtell NB, Frenkel MY, Philpot BD, Nakazawa K, Tonegawa S, Bear MF (2003) NMDA receptor-dependent ocular dominance plasticity in adult visual cortex. Neuron 38:977-985.

Shatz CJ, Stryker MP (1978) Ocular dominance in layer IV of the cat's visual cortex and the effects of monocular deprivation. J Physiol 281:267-283.

Shatz CJ, Luskin MB (1986) The relationship between the geniculocortical afferents and their cortical target cells during development of the cat's primary visual cortex. $J$ Neurosci 6:3655-3668.

Shatz CJ, Lindstrom S, Wiesel TN (1977) The distribution of afferents representing the right and left eyes in the cat's visual cortex. Brain Res 131:103-116.

Shin $\mathrm{OH}$, Lu J, Rhee JS, Tomchick DR, Pang ZP, Wojcik SM, Camacho-Perez M, Brose N, Machius M, Rizo J, Rosenmund C, Sudhof TC (2010) Munc13 C2B domain is an activity-dependent $\mathrm{Ca} 2+$ regulator of synaptic exocytosis. Nat Struct Mol Biol $17: 280-288$.

Tusa RJ, Palmer LA, Rosenquist AC (1978) The retinotopic organization of area 17 (striate cortex) in the cat. J Comp Neurol 177:213-235. 
Winfield DA (1983) The postnatal development of synapses in the different laminae of the visual cortex in the normal kitten and in kittens with eyelid suture. Brain Res 285:155-169.

Yang C, Silver B, Ellis SR, Mower GD (2001) Bidirectional regulation of mitochondrial gene expression during developmental neuroplasticity of visual cortex. Biochem Biophys Res Commun 287:1070-1074.

Yang CB, Zheng YT, Li GY, Mower GD (2002) Identification of Munc13-3 as a candidate gene for critical-period neuroplasticity in visual cortex. J Neurosci 22:8614-8618.

Yang CB, Zheng YT, Kiser PJ, Mower GD (2006) Identification of disabled-1 as a candidate gene for critical period neuroplasticity in cat and mouse visual cortex. Eur J Neurosci 23:2804-2808.

Yang CB, Kiser PJ, Zheng YT, Varoqueaux F, Mower GD (2007) Bidirectional regulation of Munc13-3 protein expression by age and dark rearing during the critical period in mouse visual cortex. Neuroscience 150:603-608.

Zikich D, Mezer A, Varoqueaux F, Sheinin A, Junge HJ, Nachliel E, Melamed R, Brose N, Gutman M, Ashery U (2008) Vesicle priming and recruitment by ubMunc13-2 are differentially regulated by calcium and calmodulin. J Neurosci 28:1949-1960.

Zucker RS (1989) Short-term synaptic plasticity. Annu Rev Neurosci 12:13-31. 


\section{CURRICULUM VITAE}

NAME: James Geoffrey Morris

ADDRESS: $\quad 6105$ Windrow Pl.

Louisville, KY 40207

DOB: $\quad$ Louisville, Kentucky - June 5, 1984

EDUCATION: B.A., Zoology, Psychology

Miami University

$2003-2007$

AWARDS: $\quad$ Honors in Medical Gross Anatomy 2008

Honors in Clinical Embryology 2009

Spirit of Miami Award 2007

EMPLOYMENT: University of Louisville School of Medicine Summer Pre-Matriculation Program

Gross Anatomy and Neuroscience Instructor 2009, Present

University of Louisville School of Medicine Medical Gross Anatomy Teaching Assistant 2009 